\title{
Microstructure of Cement Paste with Natural Pozzolanic Volcanic Ash and Portland Cement at Different Stages of Curing
}

\author{
Kunal Kupwade-Patil ${ }^{1}$, Anfal F. Al-Aibani ${ }^{2,3}$, Mohammad F. Abdulsalam ${ }^{3}$, \\ Cheahuychou Mao ${ }^{1}$, Ali Bumajdad ${ }^{2}$, Steven D. Palkovic ${ }^{1}$, Oral Büyüköztürk ${ }^{1}$ \\ ${ }^{1}$ Laboratory for Infrastructure Science and Sustainability, Department of Civil and \\ Environmental Engineering, Massachusetts Institute of Technology, Cambridge, MA 02139 \\ USA.Email: obuyuk@mit.edu; Tel:001-(617)-253-7186 \\ ${ }^{2}$ Kuwait University, Chemistry Department, P.O. Box 5969, Safat 13060, Kuwait \\ ${ }^{3}$ Energy and Building Research Center, Kuwait Institute for Scientific Research, \\ Safat 13109, Kuwait ${ }^{1}$
}

\begin{abstract}
The use of volcanic ash as a partial substitute to Portland cement can be a viable alternative for producing sustainable and durable cementitious materials. This study investigates the effect of early and late age curing of hardened cement pastes made with volcanic ash and Ordinary Portland Cement (OPC). Pore and microstructure studies were performed on hardened cement pastes prepared with $10 \%$ incremental substitution of volcanic ash up to $50 \%$ substitution of OPC. Densification in hardened cement pastes was attributed to formation of Calcium Silicate Hydrate (C-S-H) and Calcium-Alumino-Silicate-Hydrate (C-A-S-H) gels, while the development of Magnesium-Silicate-Hydrates (M-S-H) led to decalcification of C-S-H and C-A-S-H gels which resulted in an increase in porosity of the cementitious matrix. A combination of bulk and surface characterization techniques was used to facilitate effective usage of volcanic ash as a potential substitute for Portland cement that provides a sustainable construction material, and environmentally friendly solution to volcanic ash disposal.
\end{abstract}

Keywords: Volcanic Ash; Portland Cement; Microstructure; Pore Structure; Calcium Alumino Silicate Hydrate (CASH), Magnesium Silicate Hydrate (MSH) 


\section{Introduction}

As early as the second century BC the Romans began to use volcanic ash as an additive in blended cements to build highly durable structures $[1,2]$. For example, pumiceous volcanic ash was used in preparing Roman hydraulic pozzolan concrete that was used to build the Bay of Naples [2, 3]. It is known that the combination of hydraulic lime and pumiceous volcanic ash acts as a "glue" or binding agent in hydraulic pozzolan cement [4]. The volcanic ash used in the preparation of this concrete consisted of alkalis, and when the material was examined later (approximately 2000 years) showed the presence of zeolitic minerals such as analchime, phillipsite, leucite, and chabazite [4-6]. These phases are present as active constituents of zeolites and usually contribute to a high specific surface and may contain some chemically bound water that forms during the hydration of cementitious gels. Most of the volcanic ashes have some amount of inactive minerals such as feldspars, magnetite, quartz and mica which are innocuous in nature and are sometimes not involved in the hydration process when mixed with Portland Cements [5]. Despite these findings, there is a significant challenge associated with deciphering the reacted and unreacted phases during and after the hydration process [7].

Pyroclastic rocks, commonly known as volcanic rocks, originate from the eruption of magma which usually include fragments of rocks, sand and volcanic ash $[1,2,5]$. Studies indicate that only the volcanic rocks/ash that are acidic and possess high zeolitic contents demonstrate pozzolanic properties. Not all properties of pozzolan components are useful in terms of long term durability. Deleterious zeolitic phases such as montmorillonite and pholopite can cause swelling and expansion leading to internal sulfate attack if the volcanic ashes are used with aggregates that are vulnerable to alkali silica reaction (ASR), contributing to significant damage 
of the microstructures $[8,9]$. For these reasons, it is important to understand the proportion of advantageous and deleterious hydration products and the morphological development when natural pozzolans like volcanic ashes are used as an additive or partial substitute to Portland Cement.

In this study, micro and pore structures were examined for five different combinations of hardened cement pastes prepared with volcanic ash and OPC after 7, 28 and 90 days of curing. We utilize a variety of techniques consisting of X-ray Diffraction (XRD), Magic Angle Spinning Nuclear Magnetic Resonance (MAS NMR), X-ray Photolectron Spectroscopy (XPS), Back Scattered Electron Microscopy (BSE), Energy Dispersive Spectrum (EDS), optical microscopy and nitrogen adsorption. As a result, we have furthered the understanding of how to effectively substitute volcanic ash into Portland cement by considering various microstructural product formation along with the influence on pore structure.

\section{Experimental Procedure}

\subsection{Materials}

An experimental evaluation was performed to investigate the effect of curing at early (7 days), 28 days and late age (90 days) by partial replacement of Portland cement with volcanic ash. Mixes were prepared by substituting 10, 20, 30, 40 and 50\% of Portland cement with volcanic ash (See Table 1). For sample nomenclature, we refer to each mix combination based on the percent replacement of OPC with volcanic ash and age of hydration. For example, $10 \%$ substitution of volcanic ash with OPC which was cured for 7 days was designated as IP10-7, while $50 \%$ substitution of Portland cement that was cured for 28 days was designated as IP50- 
28. The samples were prepared as per ASTM C 305 [10]. The samples were cured for 7, 28 or 90 days and were inserted in acetone to retard the hydration after each curing period.

Table 1. Mix proportions and samples cured at 7, 28 and 90 days with 0.25 water to cement (w/c) ratio

\begin{tabular}{lll}
\hline Sample ID & Curing Age (Days) & Composition (\%) \\
\hline IP0-7 & 7 & OPC \\
IP10-7 & 7 & VA10-OPC90 \\
IP20-7 & 7 & VA20-OPC80 \\
IP30-7 & 7 & VA30-OPC70 \\
IP40-7 & 7 & VA40-OPC60 \\
IP50-7 & 7 & VA50-OPC50 \\
\hline IP0-28 & 28 & OPC \\
IP10-28 & 28 & VA10-OPC90 \\
IP20-28 & 28 & VA20-OPC80 \\
IP30-28 & 28 & VA30-OPC70 \\
IP40-28 & 28 & VA40-OPC60 \\
IP50-28 & 28 & VA50-OPC50 \\
\hline IP0-90 & 90 & OPC \\
IP10-90 & 90 & VA10-OPC90 \\
IP20-90 & VA20-OPC80 \\
IP30-90 & 90 & VA30-OPC70 \\
IP40-90 & 90 & VA40-OPC60 \\
IP50-90 & 90 & VA50-OPC50 \\
\hline
\end{tabular}

\subsection{Methods}

Surface and bulk structure/composition characterization was performed using X-ray Florescence (XRF) spectroscopy, Particle Size Analyzer, X-Ray Photon-electron spectroscopy (XPS), ${ }^{29} \mathrm{Si}$ Magic Angle Spinning (MAS) Nuclear Magnetic Spectroscopy (NMR), X-Ray Diffraction, Scanning Electron Microscopy (SEM), Energy Dispersive Spectra (EDS) and nitrogen sorptiometery. The list of experimental techniques that were used to study the surface and bulk structure of cementitious material is shown in Table 2. 


\begin{tabular}{|c|c|c|}
\hline Characterization Technique & Sample Type & Parameters Measured \\
\hline Qualitative and Semi-quantitative XRD & Powder & $\begin{array}{l}\text { Chemical Phases (Crystalline to } \\
\text { amorphous ratio) }\end{array}$ \\
\hline $\begin{array}{l}\text { Surface Roughness } \\
\text { Profilying System }\end{array}$ & Solid (Polished) & $\begin{array}{lrr}\text { Surface } & \text { roughness } & \text { on the } \\
\text { polished samples } & \text { before } \\
\text { SEM/BSE imaging } & \\
\end{array}$ \\
\hline $\begin{array}{l}\text { Scanning Electron } \quad \text { Microscopy } \\
\text { Energy Dispersive Spectra (EDS) }\end{array}$ & Solid (Polished) & $\begin{array}{l}\text { Details in microstructure and } \\
\text { element mapping using energy } \\
\text { dispersive spectrum (EDS) }\end{array}$ \\
\hline Optical Microscopy & Solid (Polished) & Microstructure \\
\hline $\begin{array}{l}{ }^{29} \text { Si Magic Angle Spinning (MAS) Nuclear } \\
\text { Magnetic Spectroscopy (NMR) }\end{array}$ & Powder & $\begin{array}{l}\text { Quantification of amorphous } \\
\text { phases such as C-S-H and C-A- } \\
\text { S-H gels }\end{array}$ \\
\hline $\mathrm{N}_{2}$ sorptiometry & Solid & $\begin{array}{l}\text { Pore structure and BET surface } \\
\text { area }\end{array}$ \\
\hline X-Ray Photoelectron Spectroscopy (XPS) & Powder & $\begin{array}{l}\text { Quantitative surface elemental } \\
\text { analysis }\end{array}$ \\
\hline
\end{tabular}

BET: Brunauer-Emmett-Teller

\subsubsection{Particle Size Distribution}

Particle size distribution (PSD) was conducted on volcanic ash and OPC by suspending them in isopropyl alchol using a Laser Light Scattering technique with a particle size analyzer. The mean particle size for volcanic ash and OPC was found to be $17.14 \mu \mathrm{m}$ and $12.73 \mu \mathrm{m}$, respectively (See Figure 1, Table 3). 


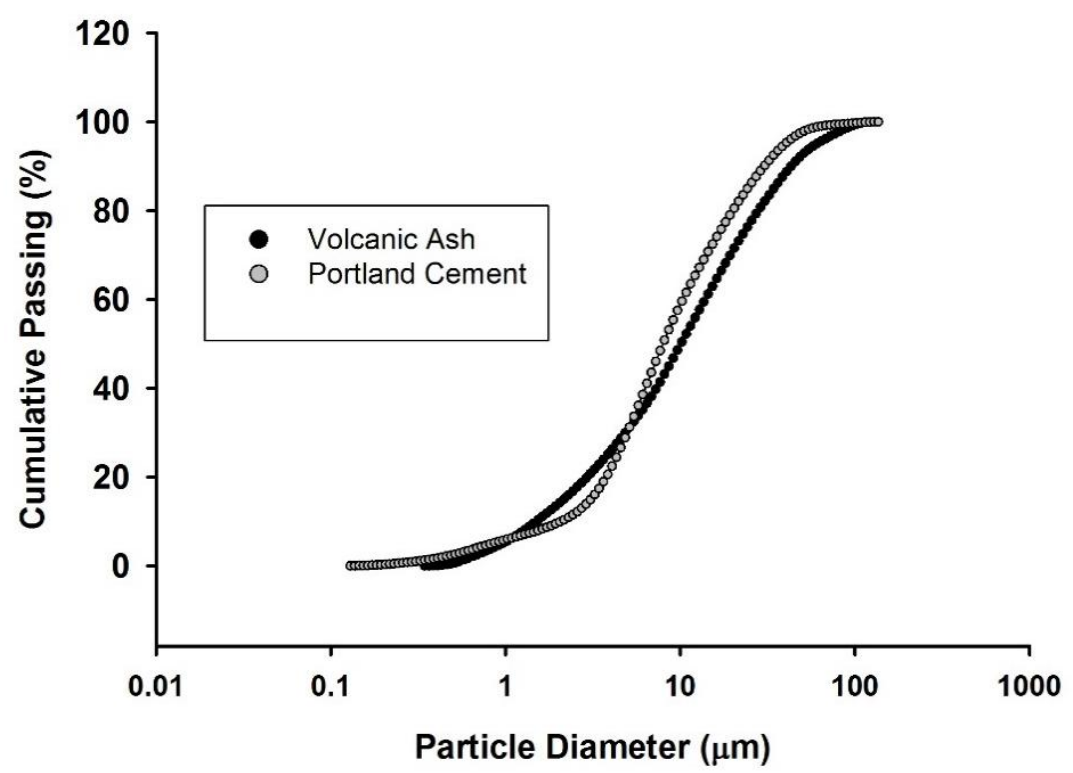

Fig 1. Paticle size distribution (PSD) analysis of volcanic ash of Saudi Arabian basaltic volcanic ash and Portland Cement.

Table 3. Particle size distribution (PSD) analysis

\begin{tabular}{|c|c|c|c|c|c|c|}
\hline & \multirow[t]{2}{*}{$\begin{array}{l}\text { Mean } \\
(\mu \mathrm{m})\end{array}$} & \multirow[t]{2}{*}{$\begin{array}{l}\text { Median } \\
(\mu \mathrm{m})\end{array}$} & \multirow[t]{2}{*}{$\begin{array}{l}\text { Mode } \\
(\mu \mathrm{m})\end{array}$} & \multicolumn{3}{|c|}{$\begin{array}{l}\text { Diameter for Selected percentiles by } \\
\text { volume }\end{array}$} \\
\hline & & & & $\mathrm{D} 90(\mu \mathrm{m})$ & $\mathrm{D} 50 \mu \mathrm{m})$ & $\mathrm{D} 10(\mu \mathrm{m})$ \\
\hline Volcanic Ash & 17.14 & 10.00 & 13.27 & 42.46 & 10.00 & 1.00 \\
\hline Portland Cement & 12.73 & 7.94 & 6.65 & 30.10 & 7.94 & 2.12 \\
\hline
\end{tabular}

\subsubsection{X-Ray Florescence Spectroscopy $(X R F)$}

The chemical composition of OPC and volcanic ash was measured using X-Ray Florescence (XRF) spectroscopy and the results are shown in Table 4. The sum of silicon oxide $\left(\mathrm{SiO}_{2}\right)$, aluminum oxide $\left(\mathrm{Al}_{2} \mathrm{O}_{3}\right)$ and ferric oxide $\left(\mathrm{Fe}_{2} \mathrm{O}_{3}\right)$ components for the raw volcanic ash is $64.3 \%$, indicating that this material is a Class C type of ash according to ASTM C 618 [11].

Table 4. Chemical composition of Ordinary Portland Cement and Volcanic Ash

\begin{tabular}{lccccccccccccc}
\hline $\begin{array}{l}\text { Chemical Composition } \\
(\%)\end{array}$ & $\mathrm{CaO}$ & $\mathrm{SiO}_{2}$ & $\mathrm{Al}_{2} \mathrm{O}_{3}$ & $\mathrm{MgO}$ & $\mathrm{SO}_{3}$ & $\mathrm{TiO}_{2}$ & $\mathrm{~K}_{2} \mathrm{O}$ & $\mathrm{Fe}_{2} \mathrm{O}_{3}$ & $\mathrm{Na}_{2} \mathrm{O}$ & $\mathrm{MnO}^{2}$ & $\mathrm{SrO}^{2}$ & $\mathrm{LOI}$ \\
Binder Type & & & & & & & & & & & & & \\
\hline OPC & 62.27 & 16.63 & 3.63 & 1.22 & 3.91 & 0.24 & 0.61 & 3.28 & 0.34 & 0.06 & 0.07 & 1.6 \\
VA & 9.09 & 38.89 & 13.00 & 6.16 & 0.14 & 2.44 & 1.31 & 12.41 & 3.12 & 0.19 & 0.07 & 1.8 \\
\hline
\end{tabular}

OPC: Ordinary Portland Cement

VA: Volcanic Ash 


\subsection{3 ${ }^{29}$ Si NMR Analysis}

Solid-state ${ }^{29}$ Si MAS NMR spectra were collected at $119.22 \mathrm{MHz}$ on a NMR spectrometer using a probe for $4 \mathrm{~mm}$ MAS BB/1H outer diameter zirconia rotors and a spinning speed of $10 \mathrm{kHz}$. The ${ }^{29} \mathrm{Si}$ MAS NMR experiments employed a pulse width of $5 \mu \mathrm{s}$, a relaxation delay of $20 \mathrm{~s}$ and 4,141 scans. All spectra were collected with a pulse angle of $51^{\circ}$. Deconvolution analysis of the ${ }^{29} \mathrm{Si}$ MAS NMR data were performed using the minimum number of components needed to describe the spectra. Gaussian functions with the full-width at half height of each component peak constrained to be less than $10 \mathrm{ppm}$ was used to fit the spectra. The peaks were assigned based on the available literature for cements. Peak widths and positions

for each identified species were held constant throughout the deconvolution process.

\subsubsection{X-Ray Diffraction}

$\mathrm{X}$-ray diffraction (XRD) was conducted using a X-Ray Diffractometer using a $\mathrm{Cu} \mathrm{K} \alpha$ radiation nickel foil filter. The ground sample was placed on Bragg-Brentano geometry optics on a flat plate sample geometry. Fixed divergence slit of 1/16 degree was chosen to limit beam overflow on the samples at small angles of $2 \theta$. Incident and diffracted-side soller slits of $0.02 \mathrm{rad}$ were used for this experiment. The X'Celerator high-speed linear detector was used for XRD experiment with an active length of 2.122 degrees $2 \theta$, a step size of 0.0167113 degrees $2 \theta$, and scan range from 4 to 90 degrees. For semi-quantitative analysis, $10 \%$ by weight of corundum was added to the sample. High score plus software from Pan Analytical was used to carry out the semi-quantitative studies using Rietveld analysis.

\subsubsection{X-Ray Photo-electron Spectroscopy}


The XPS analysis was performed with an XPS system using monochromatic Al Ka radiation $(1486.6 \mathrm{eV})$ with a spot size of $850 \mu \mathrm{m}$. The spectra acquisition and processing were carried out using a commercial software. The powdered sample was inserted on the sample holder using a double-sided carbon tape and then introduced into the preparation chamber and degassed until the proper vacuum was achieved. The sample was then transferred into the analysis chamber where the vacuum was $10^{-9}$ mbar. The analysis was carried out using the following parameters: pass energy of $20 \mathrm{eV}$, dwell time $50 \mathrm{~ms}$ and a step size of $0.1 \mathrm{eV}$.

\subsubsection{Scanning Electron Microscopy (SEM), Energy Dispersive Spectrum (EDS) and Surface} Roughness Analysis

SEM Microscopy was performed using an Environmental field Scanning Electron Microscopy (E-SEM). Scanning Electron Microscopy (SEM) was done on the unpolished sample to identify the microstructure and Backscattered Electron Microscopy (BSE) was performed on the polished samples.

An epoxy impregnation device was used to fill the pores with epoxy. The samples were then polished using a Buehler Metaserv 250 grinder polisher. The initial grit papers in size of 250, 350, 420, 600 and 800 were used for polishing using ethylene glycol. Each grit paper was used for eight minutes each. This was followed by 9,3 and $1 \mu \mathrm{m}$ oil based meta-di ultra paste with ethylene glycol polishing suspensions. The polishing for 9 and $3 \mu \mathrm{m}$ was conducted for 1 hour each, while polishing with $1 \mu \mathrm{m}$ was performed for 2 hours. The final step of polishing was done using a $0.05 \mu \mathrm{m}$ micro polish alumina with ethylene glycol for 1 hour. A $1 \mathrm{lb}$ load was applied during all stages of the polishing. The surface roughness of the polished specimen were measured using a surface profilometer. The surface 3D plot showing the surface roughness along 
the sample is shown in Figure 2. An average surface roughness of $\sim 7 \mu \mathrm{m}$ was achieved for the sample.
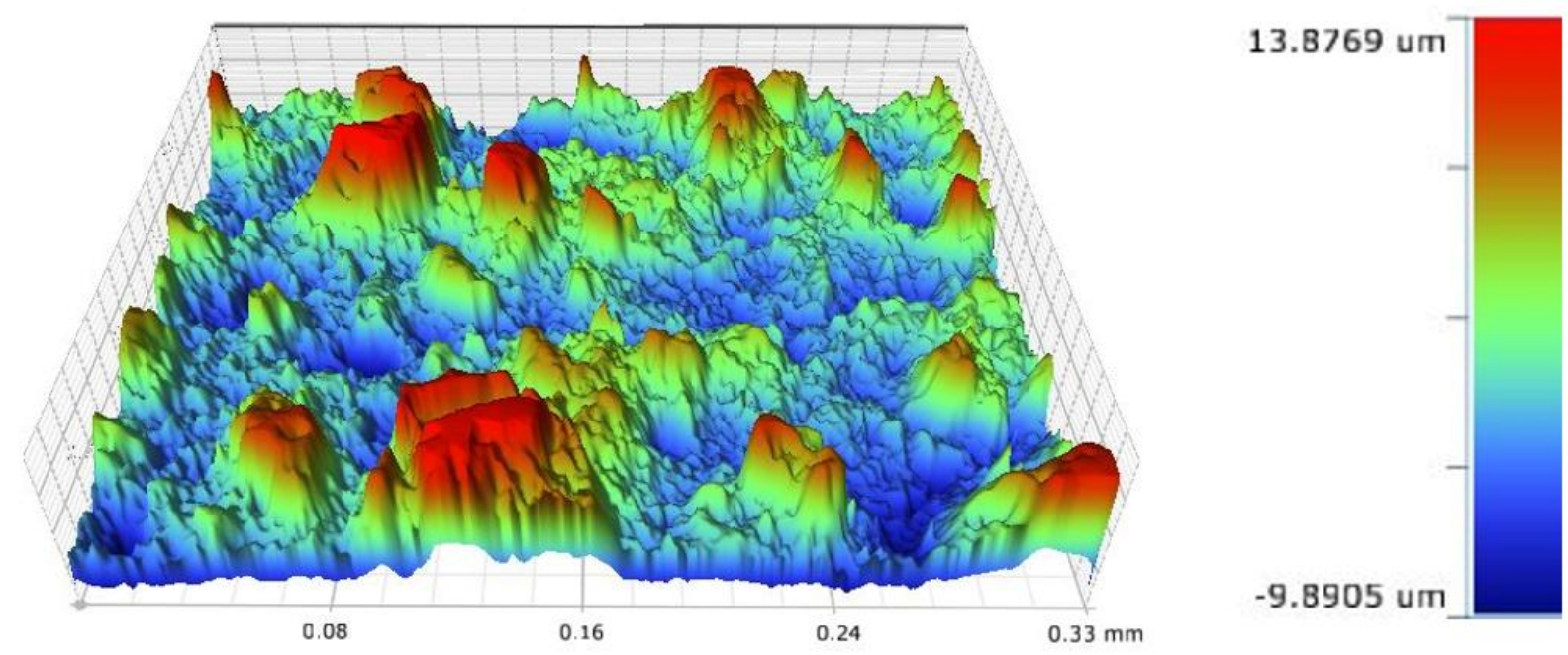

Fig 2. Topographical mapping of surface roughness analysis on a polished sample (IP-0, 28 days) used for BSE/SEM imaging

\subsubsection{Optical Microscopy}

Petrographic analysis was performed on the polished specimen using an optical microscope, and a commercial software was used to analyze the data.

\subsubsection{Nitrogen Adsorption}

Nitrogen adsorption analysis was performed on solid chunks weighing approximately $0.30 \mathrm{~g}$ that were extracted from the hardened cement paste sample. The samples were weighed before and after the analysis. Adsorption and desorption isotherms, cumulative intruded volume and surface area were calculated using the data from the nitrogen adsorption experiment. The surface area (SA) was calculated by, 


$$
\mathrm{SA}=\left(\frac{\mathrm{V}_{\mathrm{m}} \mathrm{N} \mathrm{A}}{\mathrm{V}_{\mathrm{M}}}\right) \cdot 10^{-20}
$$

where SA is the surface area $\left(\mathrm{m}^{2} / \mathrm{g}\right), \mathrm{V}_{\mathrm{m}}$ is the volume of gas adsorbed when the entire surface is covered by a monomolecular layer $\left(\mathrm{m}^{3}\right.$ per gram of absorbent), $\mathrm{A}$ is the average area occupied by one molecule of adsorbate in the completed monolayer $\left(\mathrm{m}^{2} /\right.$ molecule $), \mathrm{V}_{\mathrm{M}}$ is the molar volume $\left(\mathrm{m}^{3} / \mathrm{mol}\right)$ and $\mathrm{N}$ is the Avogadro constant.

The cumulative pore volume, $\mathrm{V}_{\mathrm{CUM}}(\mathrm{ml} / \mathrm{g})$ was calculated by,

$$
\mathrm{V}_{\mathrm{CUM}}=\mathrm{V}_{\mathrm{I}} \cdot \mathrm{D}
$$

where $V_{I}$ is the amount of gas adsorbed per gram of sample $\left(\mathrm{cm}^{3} / \mathrm{g} \mathrm{STP}\right)$ and D is the density conversion factor $\left(\mathrm{cm}^{3}\right.$ liquid $\left./ \mathrm{cm}^{3} \mathrm{STP}\right)$

\section{Results and Discussion}

\subsection{XRD Analysis}

Semi-quantitative results of XRD using Rietveld analysis for raw volcanic ash is shown in Figure

3. The crystalline part of the volcanic ash consisted of anorthite sodian (16.9\%) (PDF: 96-1008758), forsterite (9.9\%) (PDF: 96-900-0167) and calcite (1.5\%) (96-900-0966). The XRF analysis also indicated major contents of $\mathrm{CaO}(9.09 \%), \mathrm{MgO}(6.16 \%), \mathrm{Al}_{2} \mathrm{O}_{3}(13 \%)$ and $\mathrm{Na}_{2} \mathrm{O}$ (3.12\%). The amorphous component of the volcanic ash was $71.7 \%$. 


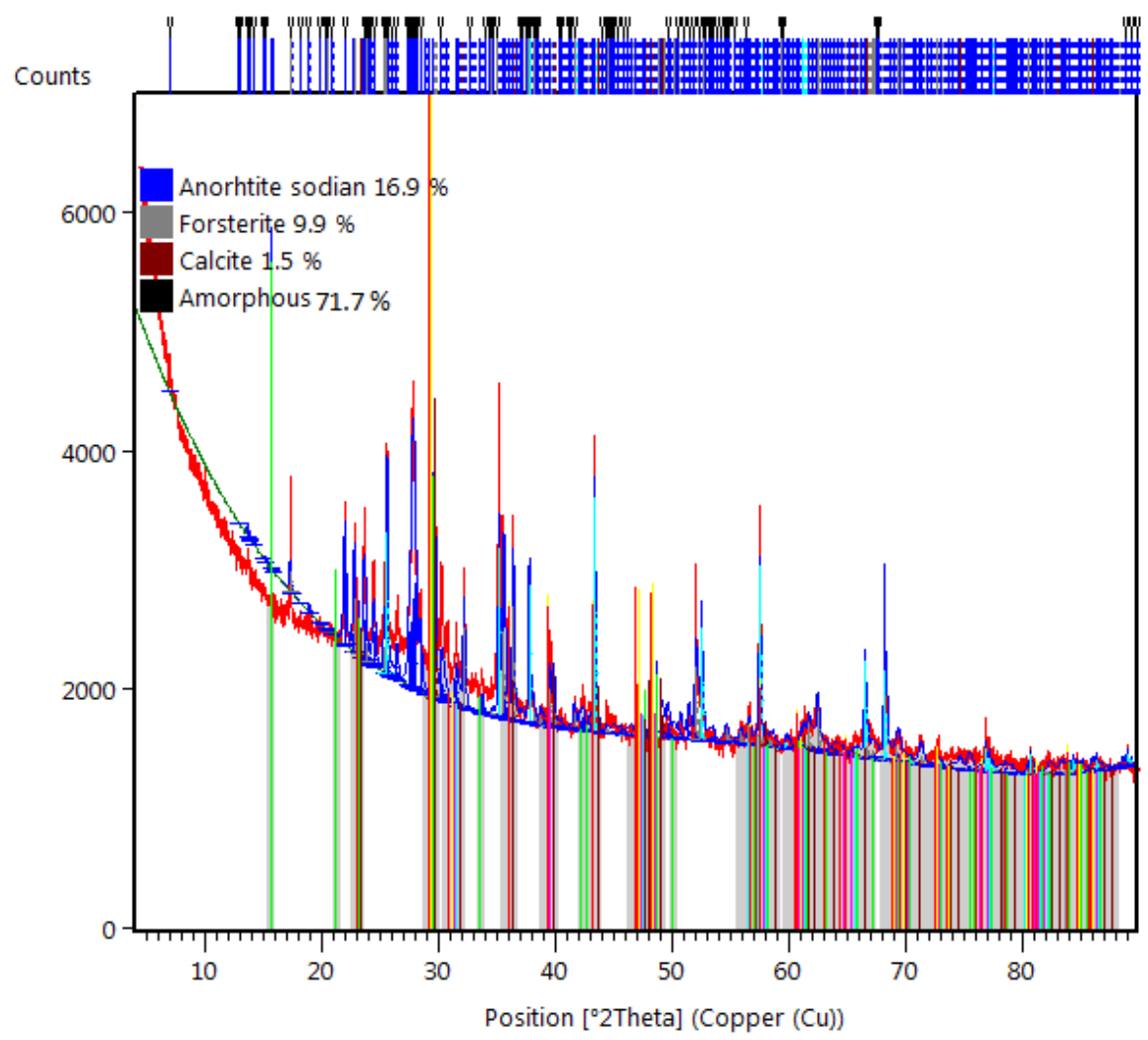

Fig 3. Semi-quantitative analysis of the volcanic ash

Semi-quantitative XRD studies for hardened cement paste samples IP10, IP30 and IP50 cured at 7, 28 and 90 days are shown in Table 5. The results show that the amorphous content increased with an increase in volcanic ash content in the mix as shown in Figure 4. The raw volcanic ash consisted of high amount of $\mathrm{Al}_{2} \mathrm{O}_{3}(13 \%)$ and $\mathrm{Na}_{2} \mathrm{O}(3.12 \%)$ compared to Portland cement $\left(\mathrm{Al}_{2} \mathrm{O}_{3}=3.63 \%, \mathrm{Na}_{2} \mathrm{O}=0.34 \%\right)$, with an overall amorphous content of $71.7 \%$. After 7 days of curing, a high $\mathrm{MgO}$ content in the form of Periclase (PDF: 96-100-0054) was observed in IP10, which decreased considerably for IP30 and IP50 samples. This shows that there was not sufficient alumina in the volcanic ash at IP10, and therefore $\mathrm{MgO}$ was not involved in the reactions forming magnesium alumino silicate hydrates (M-A-S-H). The higher amorphous content formed in IP-30 and IP-50 can be attributed to the formation of combinations of calcium silicate hydrates (C-S-H), Calcium Alumino-silicate-hydrates (C-A-S-H) along with Magnesium- 
alumino-silicate-hydrates (M-A-S-H) [12-14]. The MgO content for IP50 was higher compared to IP30, therefore M-S-H phase could have dominated in addition to C-S-H and C-A-S-H phases. Forsterite (PDF: 96-900-0268), Periclase (PDF: 96-100-0054) and Dolomite (96-900-0084) phases are associated with the crystalline part having high traces of $\mathrm{MgO}$ content which are commonly found in cementitious materials prepared with natural volcanic ash.

Table 5. Semi- Quantitative analysis for selected samples at various ages of curing

\begin{tabular}{|c|c|c|c|c|c|c|c|c|c|c|}
\hline \multirow{3}{*}{ Phase (\%) } & \multirow{3}{*}{$\begin{array}{l}\text { Volcan } \\
\text { ic Ash }\end{array}$} & \multicolumn{9}{|c|}{ Sample Type } \\
\hline & & \multirow{2}{*}{$\begin{array}{l}\text { IP- } \\
10 \\
7 \\
\text { days } \\
)\end{array}$} & \multirow{2}{*}{$\begin{array}{l}\text { IP- } \\
\text { 30 } \\
(7 \\
\text { days } \\
)\end{array}$} & \multirow{2}{*}{$\begin{array}{l}\text { IP-50 } \\
\text { (7days } \\
)^{2}\end{array}$} & \multirow{2}{*}{$\begin{array}{l}\text { IP- } \\
10 \\
(28 \\
\text { days } \\
)\end{array}$} & \multirow{2}{*}{$\begin{array}{l}\text { IP- } \\
30 \\
(28 \\
\text { days } \\
)\end{array}$} & \multirow{2}{*}{$\begin{array}{l}\text { IP- } \\
50 \\
(28 \\
\text { days } \\
)\end{array}$} & \multirow{2}{*}{$\begin{array}{l}\text { IP-10 } \\
\text { (90day } \\
\text { ) }\end{array}$} & \multirow{2}{*}{\begin{tabular}{|l|} 
IP-30 \\
(90days \\
\end{tabular}} & \multirow{2}{*}{$\begin{array}{l}\text { IP- } \\
50 \\
(90 \\
\text { days } \\
)\end{array}$} \\
\hline & & & & & & & & & & \\
\hline Amorphous & 71.7 & 71.8 & $\begin{array}{l}77.6 \\
5\end{array}$ & 82.2 & 75.8 & 79 & 84.2 & 76.7 & $\begin{array}{ll}77.3 \\
\end{array}$ & 82.7 \\
\hline $\begin{array}{l}\text { Anorthite } \\
\text { Sodian }\end{array}$ & 16.9 & & 2.8 & & & & & & 1.2 & \\
\hline Forsterite & 9.9 & & & & & & & 2.1 & 2.8 & 3 \\
\hline Calcite & 1.5 & 4.4 & 2.7 & 2.8 & 4.4 & 4.3 & 7.1 & 4.2 & 1.3 & 4.4 \\
\hline Periclase & & 7.9 & 1.9 & 2.1 & & 1.1 & 3.5 & 2.9 & 1.3 & \\
\hline Portlandite & & 13.0 & 6.25 & 3.2 & 3.6 & 4.3 & 2.4 & 5.7 & 7 & 3.2 \\
\hline Grossular & & 2.9 & 3.1 & 0.9 & & 2.1 & & & 1.4 & \\
\hline Dolomite & & & 0.8 & 1.8 & 3.3 & 1.1 & 1.3 & 2.98 & 1.6 & 4.2 \\
\hline Thenardite & & & 1.6 & 4.3 & 1.9 & 1.4 & 1.5 & 2.9 & 2.1 & 3.8 \\
\hline Lawsonite & & & 3.2 & 5.9 & 11 & 4.3 & & 2.52 & 1.5 & 1.9 \\
\hline Heulandite & & & & & & 2.4 & & & 2.5 & \\
\hline
\end{tabular}

Heulandite (96-900-0151), Lawsonite (96-900-1711), Grossular (96-900-0442) are usually associated with the crystalline part of the C-A-S-H gel phases $[15,16]$. Thenardite phase is associated with the high sulfate content present in the volcanic ash, and may have contributed to some sulfate expansion phases. An increase in volcanic ash content inceases the concentration of sulfates and alumina and provides an additional precursor for sulfate expansion [17]. 


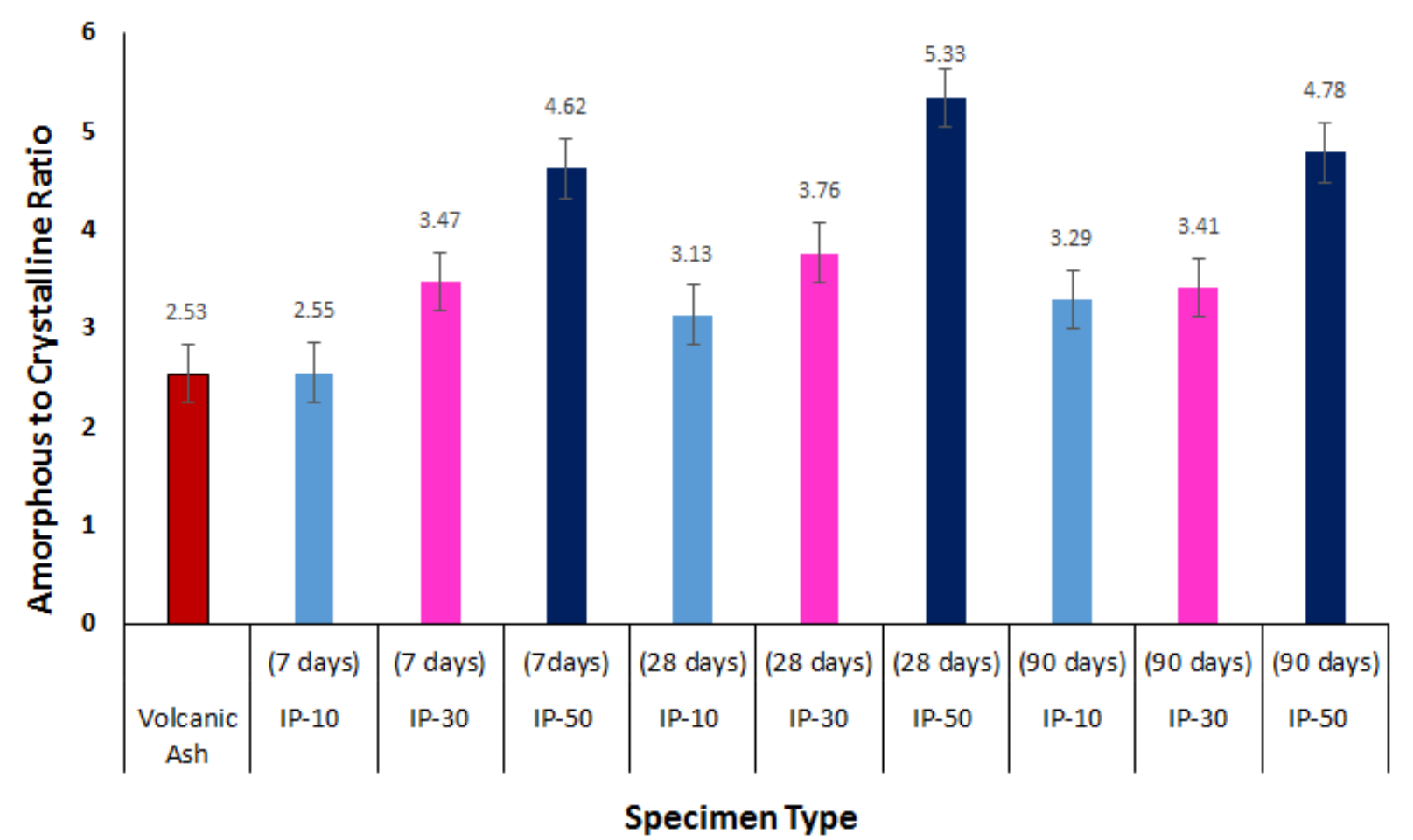

Fig 4. Amorphous to Crystalline ratio for the volcanic ash and hardened cement pastes of combination of volcanic ash and OPC after 7, 28 and 90 days.

\section{$3.2{ }^{29} \mathrm{SiNMR}$}

The deconvoluted spectra for ${ }^{29} \mathrm{Si}$ NMR for control, IP10, IP20, IP30, IP40 and IP50 after 7, 28 and 90 days are shown in Figure A1, A2 and A3, respectively (Refer to Appendix). A sample fit with $\mathrm{Q}^{\mathrm{n}}$ quantification is shown for IP40 after 90 days of curing in Figure 5. The quantification of the $\mathrm{Q}^{\mathrm{n}}$ environment after deconvolution of ${ }^{29} \mathrm{Si}$ MAS NMR after 7, 28 and 90 days for all specimen combinations is shown in Tables 6,7 and 8 , respectively. The occurrence of resonances between -74 to $-82 \mathrm{ppm}$ are associated with the formation of two types of $\mathrm{Q}^{1}$ sites with C-S-H type gels as the main reaction product [18]. According to published data [19, 20], the resonances occurring between -65 to $-73 \mathrm{ppm}$ are assigned to $\mathrm{Q}^{\circ}$. The peaks associated with $\mathrm{Q}^{\circ}$ units are the monomeric soluble silicates which act as a precursor to react with the aluminate anions $\left(\mathrm{Al}(\mathrm{OH})^{-}\right)$that are released during the dissolution of volcanic ash, resulting in 
aluminiosilicate gels. $\mathrm{Q}^{2}(1 \mathrm{Al})$ and $\mathrm{Q}^{2}(0 \mathrm{Al})$ site are associated with the formation of highly crosslinked Al-substituted C-S-H type gels also known as C-A-S-H gel [15, 16]. Studies have shown that presence of $\mathrm{Q}^{3}(1 \mathrm{Al})$ and $\mathrm{Q}^{4}(3 \mathrm{Al})$ are specific to highly crosslinked Calcium(sodium)-alumino-silicate-hydrate [C-(N)-A-S-H] type gels observed after external curing. The presence of $\mathrm{Q}^{4}(1 \mathrm{Al})$ and $\mathrm{Q}^{4}(2 \mathrm{Al})$ sites may be related to the remnant mullite in the system [20, 21]. The peak positions assigned to $-80 \mathrm{ppm},-83 \mathrm{ppm}$ and $-86 \mathrm{ppm}$ in the spectra were designated to $\mathrm{Q}^{1}, \mathrm{Q}^{2}(1 \mathrm{Al})$, and $\mathrm{Q}^{2}$ sites of the C-(N-)-A-S-H gel[22]. Myers et al. (2015) [22] assigned $\mathrm{Q}^{1}$ environments to non-isolated C-S-H gels which are dependent on the chemical shifts of $\mathrm{Q}^{1}$ sites that rely on the charge balance of $\mathrm{H}^{+}$or $\mathrm{Ca}^{+}$.

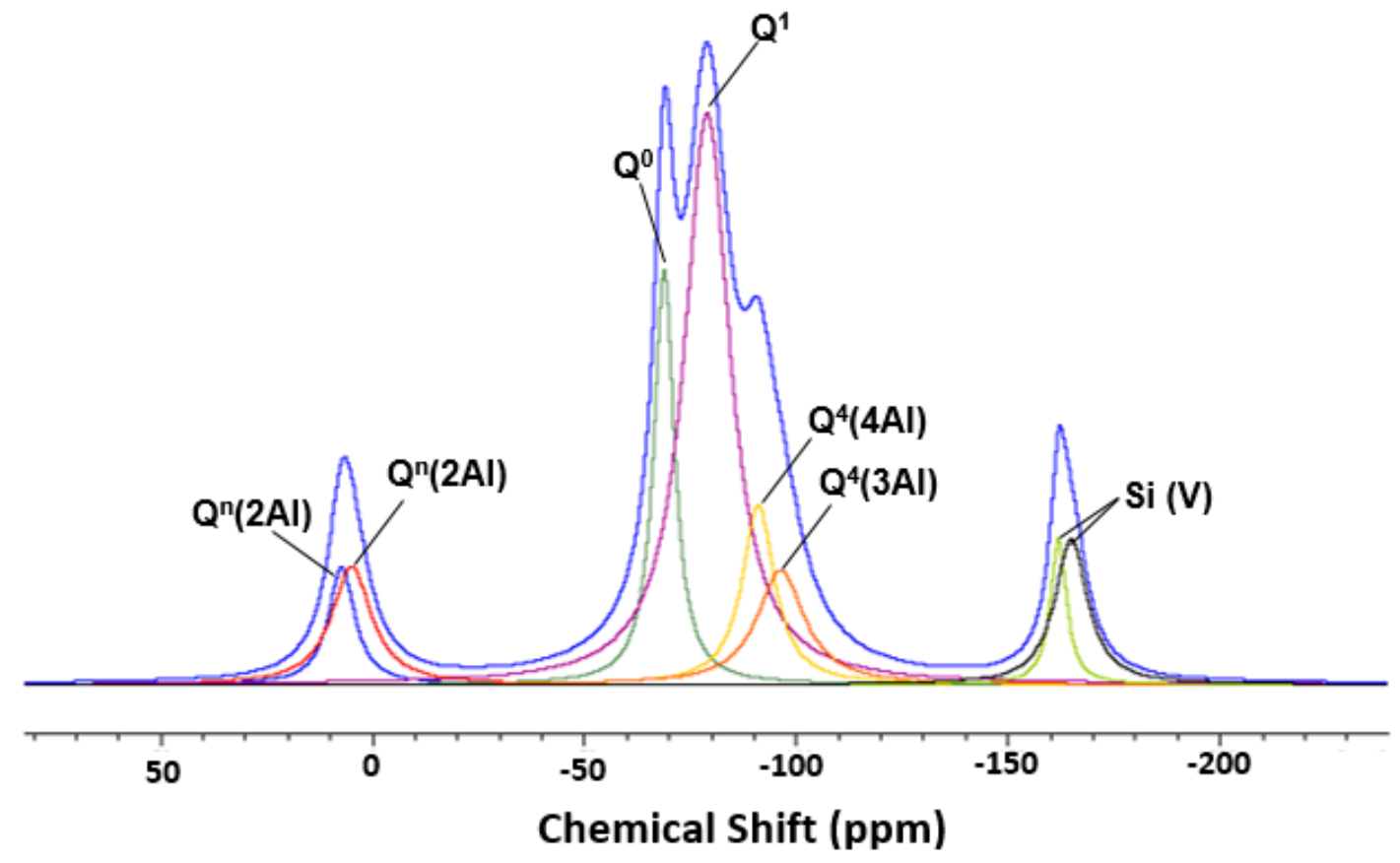

Fig 5. Deconvoluted ${ }^{29}$ Si NMR Spectra for IP40 after 90 days of curing.

In comparison to the quantification of IP50 data after 7 and 90 days, the $\mathrm{Q}^{4}(2 \mathrm{Al}), \mathrm{Q}^{4}(3 \mathrm{Al})$, $\mathrm{Q}^{4}(4 \mathrm{Al})$ and $\mathrm{Q}^{\circ}(0 \mathrm{Al})$ disappeared after 90 days of curing. An increase in $\mathrm{Q}^{\circ}$ and $\mathrm{Q}^{1}$ sites were observed at the end of 90 days of curing. These results are in good agreement with the previous studies $[15,22,23]$, where reduction in $\mathrm{Q}^{3}(1 \mathrm{Al})$ and $\mathrm{Q}^{4}(1 \mathrm{Al})$ is associated with the gradual 
transformation to $\mathrm{C}-(\mathrm{N})-\mathrm{A}-\mathrm{S}-\mathrm{H}$ gel structure possessing lower mean chain length and a relative increase in surface area. Recent studies have stated that as curing age progresses the degree of cross-linking of the C-(N)-A-S-H gel decreases over time [22]. Further MAS NMR studies are required using pure $\mathrm{C}-\mathrm{N}-\mathrm{A}-\mathrm{S}-\mathrm{H}$ gels to establish a quantitative relationship between mean chain length and reduction in surface area of the $\mathrm{C}-\mathrm{N}-\mathrm{A}-\mathrm{S}-\mathrm{H}$ gels.

Table 6. Quantification of $Q^{\mathrm{n}}$ environments and deconvolution of ${ }^{29} \mathrm{Si}$ MAS NMR spectra of 7 days

\begin{tabular}{|c|c|c|c|c|c|c|c|c|c|c|c|c|c|c|c|c|c|}
\hline \multicolumn{3}{|c|}{ Control } & \multicolumn{3}{|c|}{ IP-10 } & \multicolumn{3}{|c|}{ IP-20 } & \multicolumn{3}{|c|}{ IP-30 } & \multicolumn{3}{|c|}{ IP-40 } & \multicolumn{3}{|c|}{ IP-50 } \\
\hline ppm & \begin{tabular}{|l|} 
Area \\
$(\%)$
\end{tabular} & Assignment & ppm & \begin{tabular}{|l|} 
Area \\
$(\%)$
\end{tabular} & Assignment & ppm & $\begin{array}{l}\text { Area } \\
(\%)\end{array}$ & Assignment & ppm & \begin{tabular}{|l} 
Area \\
$(\%)$
\end{tabular} & Assignment & ppm & \begin{tabular}{|l|} 
Area \\
$(\%)$
\end{tabular} & Assignment & ppm & \begin{tabular}{|l|} 
Area \\
$(\%)$
\end{tabular} & Assignment \\
\hline-159 & 3.92 & $\mathrm{Si}(\mathrm{V})$ & -1670 & 0.57 & $\mathrm{Si}(\mathrm{V})$ & -164 & 2.86 & $\mathrm{Si}(\mathrm{V})$ & -166 & 0.43 & $\mathrm{Si}(\mathrm{V})$ & -164 & 3.27 & $\mathrm{Si}(\mathrm{V})$ & -152 & 0.75 & $\mathrm{Si}(\mathrm{V})$ \\
\hline-151 & 4.26 & $\mathrm{Si}(\mathrm{V})$ & -1521 & 1.83 & $\mathrm{Si}(\mathrm{V})$ & -160 & 1.47 & $\mathrm{Si}(\mathrm{V})$ & -158 & 3.85 & $\mathrm{Si}(\mathrm{V})$ & -152 & 2.12 & $\mathrm{Si}(\mathrm{V})$ & -106 & 6.02 & $\mathrm{Q}^{4}(0 \mathrm{Al})$ \\
\hline-79 & \multicolumn{2}{|c|}{$14.61 \mathrm{Q}^{1}$} & \begin{tabular}{l|l}
-80 & 2 \\
\end{tabular} & \multicolumn{2}{|c|}{$25.17 \mathrm{Q}^{1}$} & -158 & 5.18 & $\mathrm{Si}(\mathrm{V})$ & -151 & 2.3 & $\mathrm{Si}(\mathrm{V})$ & -87 & \multicolumn{2}{|c|}{$4.26 \mathrm{Q}^{4}(4 \mathrm{Al})$} & -100 & 6.65 & $\mathrm{Q}^{4}(2 \mathrm{Al})$ \\
\hline-75 & \multicolumn{2}{|c|}{$35.98 \mathrm{Q}^{1}$} & -763 & \multicolumn{2}{|c|}{$36.39 \mathrm{Q}^{1}$} & -151 & 5.42 & $\mathrm{Si}(\mathrm{V})$ & -93 & 1.95 & $\mathrm{Q}^{4}(3 \mathrm{Al})$ & -80 & \multicolumn{2}{|c|}{$23.15 \mathrm{Q}^{1}$} & -94 & 12.88 & $\mathrm{Q}^{4}(3 \mathrm{Al})$ \\
\hline-67 & \multicolumn{2}{|c|}{$36.53 \mathrm{Q}^{0}$} & -68 & \multicolumn{2}{|c|}{$30.72 \mathrm{Q}^{0}$} & -79 & \multicolumn{2}{|c|}{$19.04 Q^{1}$} & -87 & 7.85 & $\mathrm{Q}^{4}(4 \mathrm{Al})$ & -76 & \multicolumn{2}{|c|}{$27.12 \mathrm{Q}^{1}$} & -90 & 10.95 & $\mathrm{Q}^{4}(4 \mathrm{Al})$ \\
\hline 7 & 1.36 & $\mathrm{Q}^{\mathrm{n}}(2 \mathrm{Al})$ & 2 & 1.41 & $\mathrm{Q}^{\mathrm{n}}(1 \mathrm{Al})$ & -75 & 29.41 & & -79 & 14.4 & $\mathrm{Q}^{1}$ & -68 & 23.89 & $\mathrm{Q}^{0}$ & -85 & 4.08 & $\mathrm{Q}^{2}(0 \mathrm{Al})$ \\
\hline \multirow[t]{6}{*}{17} & 3.35 & $\mathrm{Q}^{\mathrm{n}}(2 \mathrm{Al})$ & 16 & 3.92 & $\mathrm{Q}^{\mathrm{n}}(2 \mathrm{Al})$ & -67 & \multicolumn{2}{|c|}{$28.77 \mathrm{Q}^{0}$} & -78 & 25.3 & $\mathrm{Q}^{1}$ & 7 & 7.98 & $\mathrm{Q}^{\mathrm{n}}(2 \mathrm{Al})$ & -79 & \multicolumn{2}{|c|}{$23.14 \mathrm{Q}^{1}$} \\
\hline & & & & & & 3 & 2.1 & $\mathrm{Q}^{\mathrm{n}}(1 \mathrm{Al})$ & -75 & 22.63 & $\mathrm{Q}^{1}$ & 16 & 8.23 & $\mathrm{Q}^{\mathrm{n}}(2 \mathrm{Al})$ & -77 & 19.17 & $\mathrm{Q}^{1}$ \\
\hline & & & & & & 4 & 0.11 & $\mathrm{Q}^{\mathrm{n}}(1 \mathrm{Al})$ & -67 & 15.61 & $\mathrm{Q}^{0}$ & & & & -68 & 9.63 & $\mathrm{Q}^{0}$ \\
\hline & & & & & & 9 & 3.34 & $\mathrm{Q}^{\mathrm{n}}(2 \mathrm{Al})$ & 2 & 3.57 & $\mathrm{Q}^{\mathrm{n}}(1 \mathrm{Al})$ & & & & 15 & 6.72 & $\mathrm{Q}^{\mathrm{n}}(2 \mathrm{Al})$ \\
\hline & & & & & & 16 & 2.3 & $\mathrm{Q}^{\mathrm{n}}(2 \mathrm{Al})$ & 7 & 0.33 & $\mathrm{Q}^{\mathrm{n}}(2 \mathrm{Al})$ & & & & & & \\
\hline & & & & & & & & & 17 & 1.79 & $\mathrm{Q}^{\mathrm{n}}(2 \mathrm{Al})$ & & & & & & \\
\hline
\end{tabular}

The effect of magnesium on the reaction products can be observed by attributing the peaks around $10 \mathrm{ppm}$ [24]. Hydrotalcite is one of the predominant phases that are structurally related to brucite and periclaise. Since the volcanic ash had higher contents of aluminum and magnesium, the $\mathrm{Mg}^{2+}$ ions which were octahedrally coordinated were replaced by tripositive $\mathrm{Al}^{3+}$, while the charge was being balanced by anions that are involved in interlayer sites in conjunction with $\mathrm{H}_{2} \mathrm{O}$ molecules [25]. Although alumina is present in $\mathrm{C}-\mathrm{S}-\mathrm{H}$, which exists in a 4fold coordination, magnesium and aluminum in the hydroxide phase having 6-fold aluminum must be completely accountable for peaks around $10 \mathrm{ppm}$. 
The chemical shift of ${ }^{29} \mathrm{Si}$ spectra is predominately dominated by the degree of connectivity of the silica tetrahedra [26]. The peaks associated between 3 to $5 \mathrm{ppm}$ corresponds to $\mathrm{Q}^{\mathrm{n}}(1 \mathrm{Al})$. $\mathrm{A}$ similar behavior is shown if the silicate is involved with two aluminate neighbor as the chemical shift moves from 5 to $10 \mathrm{ppm}$ and is noted as $\mathrm{Q}^{\mathrm{n}}(2 \mathrm{Al})[26]$.

Table 7. Quantification of $Q^{\mathrm{n}}$ environments and deconvolution of ${ }^{29} \mathrm{Si}$ MAS NMR spectra of 28 days

\begin{tabular}{|c|c|c|c|c|c|c|c|c|c|c|c|c|c|c|c|c|c|}
\hline \multicolumn{3}{|c|}{ Control } & \multicolumn{3}{|c|}{ IP-10 } & \multicolumn{3}{|l|}{ IP20 } & \multicolumn{3}{|c|}{ IP-30 } & \multicolumn{3}{|c|}{ IP-40 } & \multicolumn{3}{|c|}{ IP-50 } \\
\hline ppm & $\begin{array}{l}\text { Area } \\
(\%)\end{array}$ & $\begin{array}{l}\text { Assign } \\
\text { ment }\end{array}$ & $\begin{array}{l}\text { pp } \\
\text { m }\end{array}$ & $\begin{array}{l}\text { Area } \\
(\%)\end{array}$ & $\begin{array}{l}\text { Assign } \\
\text { ment }\end{array}$ & ppm & $\begin{array}{l}\text { Area } \\
(\%)\end{array}$ & $\begin{array}{l}\text { Assign } \\
\text { ment }\end{array}$ & ppm & $\begin{array}{l}\text { Area } \\
(\%)\end{array}$ & $\begin{array}{l}\text { Assign } \\
\text { ment }\end{array}$ & ppm & $\begin{array}{l}\text { Area } \\
(\%)\end{array}$ & $\begin{array}{l}\text { Assign } \\
\text { ment }\end{array}$ & ppm & $\begin{array}{l}\text { Area } \\
(\%)\end{array}$ & $\begin{array}{l}\text { Assign } \\
\text { ment }\end{array}$ \\
\hline-159 & 9.49 & $\mathbf{S i}(\mathbf{V})$ & -162 & 7.71 & $\mathbf{S i}(\mathbf{V})$ & -162 & 1.39 & $\operatorname{Si}(\mathbf{V})$ & -163 & 2.56 & $\mathbf{S i}(\mathbf{V})$ & -160 & 2.06 & $\operatorname{Si}(\mathbf{V})$ & -174 & 6.57 & $\mathbf{S i}(\mathbf{V})$ \\
\hline-154 & 17.92 & $\mathrm{Si}(\mathrm{V})$ & -160 & 7.00 & $\operatorname{Si}(\mathbf{V})$ & -152 & 1.88 & $\operatorname{Si}(V)$ & -160 & 4.77 & $\mathrm{Si}(\mathrm{V})$ & -151 & 0.25 & $\operatorname{Si}(V)$ & -164 & 10.78 & $\mathrm{Si}(\mathrm{V})$ \\
\hline-80 & 14.62 & $Q^{1}$ & -154 & 17.10 & $\mathrm{Si}(\mathrm{V})$ & -79 & $\begin{array}{l}28.0 \\
3\end{array}$ & $Q^{1}$ & -158 & 10.70 & $\mathrm{Si}(\mathrm{V})$ & -99 & 3.59 & $Q^{4}(3 \mathrm{Al})$ & -152 & 1.13 & $\mathrm{Si}(\mathrm{V})$ \\
\hline-75 & 28.84 & $Q^{1}$ & -80 & 16.62 & $Q^{1}$ & -76 & $\begin{array}{l}35.6 \\
9\end{array}$ & $Q^{1}$ & -151 & 3.96 & $\operatorname{Si}(\mathbf{V})$ & -92 & 0.57 & $Q^{4}(4 \mathrm{Al})$ & -78 & 40.77 & $Q^{1}$ \\
\hline-67 & 26.47 & $\mathbf{Q}^{0}$ & -75 & 25.96 & $Q^{1}$ & -68 & $\begin{array}{l}27.7 \\
1\end{array}$ & $Q^{0}$ & -78 & 21.80 & $Q^{1}$ & -87 & 36.42 & $Q^{3}(1 \mathrm{Al})$ & -77 & 21.88 & $Q^{1}$ \\
\hline 8 & 0.99 & $Q^{n}(2 A I)$ & -67 & 23.32 & $Q^{0}$ & 7 & 1.15 & $Q^{n}(2 A l)$ & -75 & 28.81 & $Q^{1}$ & -80 & 24.97 & $Q^{1}$ & -68 & 10.78 & $Q^{0}$ \\
\hline 17 & 1.66 & $Q^{n}(2 A I)$ & 3 & 0.32 & $Q^{n}(2 A l)$ & 16 & 4.15 & $Q^{n}(2 A l)$ & -67 & 21.62 & $Q^{0}$ & -77 & 22.43 & $Q^{1}$ & 3 & 4.51 & $Q^{n}(2 A l)$ \\
\hline & & & 7 & 1.2 & $Q^{n}(2 A I)$ & & & & 2 & 3.14 & $Q^{n}(2 A l)$ & -68 & 9.35 & $\mathbf{Q}^{\mathbf{0}}$ & 7 & 1.73 & $Q^{n}(2 A l)$ \\
\hline & & & 16 & 0.77 & $Q^{n}(2 \mathrm{Al})$ & & & & 10 & 2.16 & $Q^{n}(2 A l)$ & 3 & 0.28 & $Q^{n}(2 A l)$ & 16 & 1.85 & $Q^{n}(2 A l)$ \\
\hline & & & & & & & & & 16 & 2.95 & $Q^{n}(2 A l)$ & 15 & 0.09 & $Q^{n}(2 A I)$ & & & \\
\hline
\end{tabular}

In the literature, peaks associated with -66 ppm are assigned to $\mathrm{Mg}_{20} \mathrm{Si}_{6} \mathrm{H}_{8} \mathrm{O}_{36}$ or superhydrous phase $\mathrm{B}$ obtained by cross-polarization with ${ }^{1} \mathrm{H}$ along with the tetrahedral resonances that are usually observed at $-64,-78$, and $-75 \mathrm{ppm}$ positions reported for octahedral $\mathrm{Si}$ [27]. Forsterite and $\beta-\mathrm{Mg}_{2} \mathrm{SiO}_{4}$ are associated with peaks at $-61.8 \mathrm{ppm}$ and $-79 \mathrm{ppm}$, respectively. Hydrous magnesium silicate phases are present due to the unreacted volcanic ash for $50 \%$ substitution of volcanic ash with Portland cement (IP50) [12]. It also can be observed that by addition of volcanic ash, an incremental increase from $-162.33 \mathrm{ppm}$ (OPC) to $-173.9 \mathrm{ppm}$ (IP-50) after 28 days of curing while further increasing to -177 ppm after 90 days of curing. Phillips et al. 1997 [28] assigned the peaks around -173 ppm to $\mathrm{Mg}_{12} \mathrm{Si}_{4} \mathrm{O}_{19}(\mathrm{OH})_{2}$. These results indicate that increase in the volcanic ash content and higher curing times led to additional crystallization forming various types of hydrous magnesium silicates. 
Resonances near -100 ppm were observed for IP50 and IP40 after 7 and 28 days, respectively, and are attributed to magnesium silicate hydrate (M-S-H) [29]. M-S-H has been characterized as a poorly crystallized phase with a chemical formula of $\mathrm{M}_{3} \mathrm{~S}_{2} \mathrm{H}_{2}$ (where $\mathrm{M}=\mathrm{MgO}, \mathrm{S}=\mathrm{SiO}_{2}, \mathrm{H}$ $=\mathrm{H}_{2} \mathrm{O}$ ). After 28 days of curing, resonance at $-87.49 \mathrm{ppm}$ and a shoulder of $-99.27 \mathrm{ppm}$ was observed for IP40 that was attributed to the M-S-H phase that previous studies have assigned a $\mathrm{Mg} / \mathrm{Si}$ ratio between 0.66 and 0.80 [28].

After 90 days of curing, -89 ppm resonance was observed in IP30 that can also be attributed to the $\mathrm{M}-\mathrm{S}-\mathrm{H}$ phase with $\mathrm{Mg} / \mathrm{Si}$ ratio of 0.66. At an early age, only traces of $\mathrm{M}-\mathrm{S}-\mathrm{H}$ were observed in IP50, and after 28 days of curing IP40 showed a presence of M-S-H phase. M-S-H was detected on IP30 after 90 days of curing. This clearly indicates higher contents of Mg from M-S$\mathrm{H}$ at early age in IP50, while after curing for 28 days both IP40 and IP30 showed traces of M-S$\mathrm{H}$ phase. No signs of M-S-H phase was observed among IP10 and IP20 during early stages of curing. In addition, XRD studies showed that excess Mg from the volcanic ash may be involved in forming magnesium based crystalline phase such as forsterite and periclase.

Table 8. Quantification of $Q^{n}$ environments and deconvolution of ${ }^{29}$ Si MAS NMR spectra of 90 days

\begin{tabular}{|c|c|c|c|c|c|c|c|c|c|c|c|c|c|c|c|c|c|}
\hline \multicolumn{3}{|c|}{ Control } & \multicolumn{3}{|c|}{ IP-10 } & \multicolumn{3}{|l|}{ IP20 } & \multicolumn{3}{|l|}{ IP-30 } & \multicolumn{3}{|l|}{ IP-40 } & \multicolumn{3}{|l|}{ IP-50 } \\
\hline ppm & $\begin{array}{l}\text { Area } \\
(\%)\end{array}$ & $\begin{array}{l}\begin{array}{l}\text { Assignm } \\
\text { ent }\end{array} \\
\end{array}$ & $\overline{p p m}$ & $\begin{array}{l}\text { Area } \\
(\%)\end{array}$ & $\begin{array}{l}\text { Assignm } \\
\text { ent }\end{array}$ & ppm & $\begin{array}{l}\text { Area } \\
(\%)\end{array}$ & $\begin{array}{l}\text { Assignm } \\
\text { ent }\end{array}$ & ppm & $\begin{array}{l}\text { Area } \\
(\%)\end{array}$ & $\begin{array}{l}\text { Assignm } \\
\text { ent }\end{array}$ & ppm & $\begin{array}{l}\text { Area } \\
(\%)\end{array}$ & $\begin{array}{l}\text { Assignm } \\
\text { ent }\end{array}$ & ppm & $\begin{array}{l}\text { Area } \\
(\%)\end{array}$ & $\begin{array}{l}\text { Assignm } \\
\text { ent }\end{array}$ \\
\hline-164 & 3.54 & $\operatorname{Si}(\mathbf{V})$ & -162 & 2.72 & $\operatorname{Si}(\mathbf{V})$ & -162 & 5.17 & $\mathbf{S i}(\mathbf{V})$ & -168 & 6.08 & $\mathbf{S i}(\mathbf{V})$ & -165 & 7.85 & $\mathbf{S i}(\mathbf{V})$ & -177 & 1.92 & $\operatorname{Si}(\mathbf{V})$ \\
\hline-152 & 4.14 & $\mathbf{S i}(\mathbf{V})$ & -152 & 4.27 & $\mathbf{S i}(\mathbf{V})$ & -153 & 2.77 & $\mathbf{S i}(\mathbf{V})$ & -164 & 4.58 & $\mathbf{S i}(\mathbf{V})$ & -162 & 3.83 & $\mathbf{S i}(\mathbf{V})$ & -162 & 8.73 & $\operatorname{Si}(\mathbf{V})$ \\
\hline-79 & 25.18 & $Q^{1}$ & -79 & 12.98 & $Q^{1}$ & -80 & 29.52 & $Q^{1}$ & -161 & 3.19 & $\operatorname{Si}(\mathbf{V})$ & -96 & 8.96 & $Q^{4}(3 \mathrm{AI})$ & -162 & 5.70 & $\operatorname{Si}(\mathbf{V})$ \\
\hline-75 & 36.71 & $Q^{1}$ & -76 & 27.75 & $Q^{1}$ & -76 & 35.25 & $\mathbf{Q}^{1}$ & -89 & 10.86 & $Q^{3}(1 \mathrm{Al})$ & -91 & 9.58 & $Q^{4}(4 A I)$ & -159 & 4.18 & $\operatorname{Si}(\mathbf{V})$ \\
\hline-67 & 27.69 & $\mathbf{Q}^{0}$ & -68 & 20.31 & $Q^{0}$ & -68 & 22.48 & $Q^{0}$ & -80 & 20.87 & $\mathbf{Q}^{1}$ & -79 & 42.86 & $\mathbf{Q}^{1}$ & -151 & 1.16 & $\mathrm{Si}(\mathbf{V})$ \\
\hline 8 & 0.14 & $\mathbf{Q}^{\mathrm{n}}(\mathbf{2 A l})$ & 6 & 4.61 & $Q^{\mathrm{n}}(\mathbf{2 A I})$ & 7 & 0.44 & $\mathbf{Q}^{\mathrm{n}}(\mathbf{2 A l})$ & -76 & 26.85 & $Q^{1}$ & -69 & 14.01 & $\mathbf{Q}^{0}$ & -79 & 14.26 & $Q^{1}$ \\
\hline 16 & 2.60 & $Q^{\mathrm{n}}(\mathbf{2 A l})$ & 15 & 27.36 & $\mathbf{Q}^{\mathrm{n}}(\mathbf{2 A l})$ & 17 & 4.37 & $Q^{n}(2 A I)$ & -67 & 13.21 & $\mathbf{Q}^{0}$ & 5 & 7.80 & $\mathbf{Q}^{\mathrm{n}}(\mathbf{2 A l})$ & -77 & 21.98 & $\mathbf{Q}^{1}$ \\
\hline & & & & & & & & & 4 & 2.39 & $Q^{\mathrm{n}}(\mathbf{1 A l})$ & 7 & 5.09 & $\mathbf{Q}^{\mathrm{n}}(\mathbf{2 A I})$ & -76 & 14.80 & $\mathbf{Q}^{1}$ \\
\hline & & & & & & & & & 7 & 3.04 & $Q^{n}(2 A I)$ & & & & -70 & 10.71 & $\mathbf{Q}^{0}$ \\
\hline & & & & & & & & & 8 & 6.52 & $\mathbf{Q}^{\mathbf{n}}(\mathbf{2 A I})$ & & & & -67 & 6.46 & $\mathbf{Q}^{0}$ \\
\hline & & & & & & & & & 17 & 2.41 & $Q^{n}(2 A l)$ & & & & -6 & 0.52 & $\mathbf{Q}^{0}$ \\
\hline & & & & & & & & & & & & & & & 5 & 3.08 & $Q^{n}(2 A l)$ \\
\hline & & & & & & & & & & & & & & & 9 & 4.11 & $Q^{n}(2 A l)$ \\
\hline & & & & & & & & & & & & & & & 17 & 2.38 & $Q^{n}(2 A I)$ \\
\hline
\end{tabular}

\subsection{Scanning Electron Microscopy}

An SEM micrograph of the unpolished sample for IP20 after 90 days of hydration is shown in

Figure 6. The unreacted volcanic ash after 90 days is present as a spherical ball as shown in

Figure 6A. Secondary zeolitic crystal growth was observed on the surface of the unreacted 
volcanic ash crystal. A magnified image of the Ca-based zeolites with lengths varying between $2-4 \mu \mathrm{m}$ is shown in Figure 6B [4]. In addition to zeolitic growth of the crystals, calcium hydroxide crystals that are flat and hexagonal in shape were detected (See Figure 6A). Furthermore, hexagonal tubular shaped zeolite crystals are shown in Figure 6C. The EDS elemental analysis along with elemental mapping is shown in Figure 6D. Traces of sulfur, alumina, sodium and calcium were observed on the zeolite crystals. As seen in XRD analysis, these zeolitic crystals could be attributed to thenardite along with darapskite [30]. The inclusion of volcanic ash increased the alumina, calcium, sodium and sulfate content in the mix due to the high content from the volcanic ash ( $\mathrm{Al}, \mathrm{Si}, \mathrm{Mg}$, and $\mathrm{Na})$. The excess content that was not involved in the formation of amorphous phases such as C-S-H, C-A-S-H and M-S-H gels formed sodium sulfate bearing zeolites such as thernardite and darapskite [31]. 


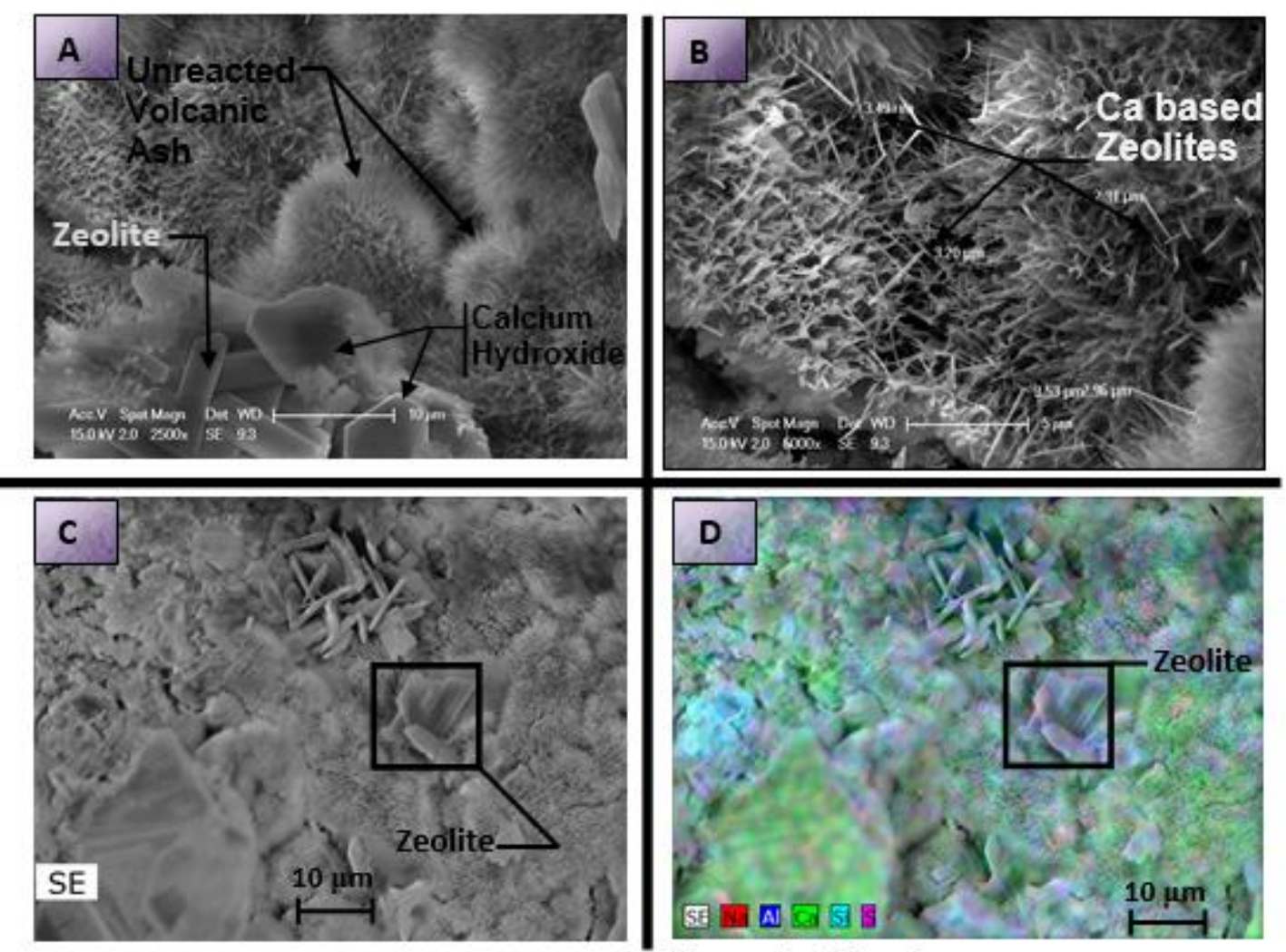

Elemental Mapping

Fig 6. SEM micrograph of IP-20 after 90 days of curing

Volcanic materials mostly contain zeolitic phases consisting of tectosilicate mineral groups that contain a framework of alumino-silicate tetrahedral [32]. Previous studies show that natural pozzolans such as volcanic tuffs showed higher pozzolanic activity and are more chemically reactive than industrial by-products such as fly ash or blast furnace slag [31, 33]. The zeolitic tuffs are predominatly controlled by cations that are exchangeable with the pore solution causing an increase in pozzolanic reaction leading to significant exchange of $\mathrm{Ca}^{2+}$ ions. The calcium based zeolitic structure could be associated to the Ca-rich chabazite $\left(\mathrm{Ca}_{2} \mathrm{Al}_{4} \mathrm{Si}_{8} \mathrm{O}_{24} \cdot 12 \mathrm{H}_{2} \mathrm{O}\right)$ representing natural zeolites with a high order of crystallinity [32, 33].

Polished sample of hardened cement paste prepared with $10 \%$ volcanic ash and $90 \%$ Portland cement is shown in Figure 7. A zeolite crystal was observed on the unreacted volcanic ash. 
Prolonged curing for 90 days allowed the alumina content on surface to form zeolites. A uniform secondary growth with an equidistant spacing of $80.40 \mathrm{~nm}$ was observed along with the length of crystals varying from 1.62 to $1.81 \mu \mathrm{m}$.

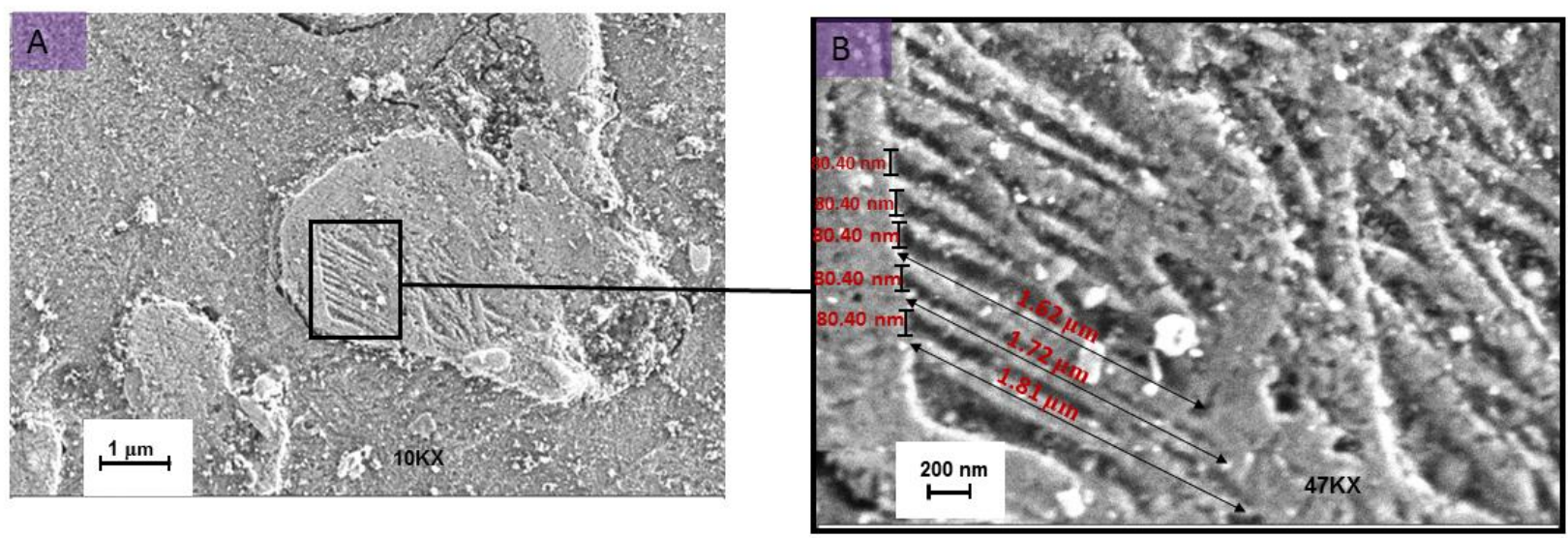

Fig 7. A. Scanning electron micrograph showing secondary zeolitic reactions inside the ash particle on hardened cement prepared with $10 \%$ volcanic ash and $90 \%$ Portland Cement after 90 days of curing; B. Almost similar growth length of the crystals showing equidistant spacing of growth

As shown by the XRD results, the amorphous content increased with curing allowing post recrystallization due to the availability of the amorphous aluminiosilicate from the unreacted volcanic ash which formed zeolites on the surface of the unreacted volcanic ash (See Figure 6 A). Studies have shown that nucleation of zeolite systems from the addition of fly ash or metakaolin occur via hydration shells of cations from aluminate or silicate precursors [34-36]. The rate of nucleation depends on several factors such as the availability of alumina/sodium/calcium from the unhydrated particles, nature of solid to liquid interaction, curing condition and the $\mathrm{pH}$ environment of the system. Additional studies are required to understand the exact mechanism of formation that leads to uniform positioning of the zeolitic crystals with an equidistant nanometer level spacing.

SEM image of a polished specimen for a hardened cement paste prepared with $50 \%$ volcanic ash and $50 \%$ Portland cement is shown in Figure 8A. Elemental and phase mapping using energy 
dispersive spectrum (EDS) are shown in Figures 8B and 8C, respectively. Phase mapping is a technique which allows for the detection of phases depending on the chemical content by combining individual elements forming that phase. Although this technique may be helpful to detect volume fraction and morphology of phases, the inability to track hydrogen through EDS may not be accurate for amorphous phases or crystalline products with hydrogen elements. In this study, MAS NMR was used to interpret the amorphous phases for the various combinations as shown in section 3.2. The elemental composition showed 5\% $\mathrm{Mg}, 35 \% \mathrm{Al}$ and $21 \% \mathrm{Si}, 13 \%$ $\mathrm{Ca}$ and $3 \% \mathrm{Fe}$. The phase mapping showed 5\% of $\mathrm{Mg}, \mathrm{Si}, \mathrm{O}, \mathrm{Al}$ and $\mathrm{Fe}$ suggesting magnesium dominated phases. This indicates that significant magnesium along with $\mathrm{Al}$ and Si were present in IP40 associated with crystalline phases related to magnesium. XRD analysis showed the presence of fosterite $\left(\mathrm{Mg}_{7.2} \mathrm{Fe}_{0.80} \mathrm{Si}_{4} \mathrm{O}_{16}\right)$, periclase $\left(\mathrm{Mg}_{4} \mathrm{O}_{4}\right)$ and dolomite $\left(\mathrm{Ca}_{3} \mathrm{Mg}_{3} \mathrm{C}_{6} \mathrm{O}_{18}\right)$ that could be related to the phase detected by EDS phase mapping. The bulk of the phases were $39 \%(\mathrm{Al}, \mathrm{O}, \mathrm{Si}$ and $\mathrm{Ca}), 24 \%$ of $(\mathrm{Si} / \mathrm{Al} / \mathrm{Ca} / \mathrm{O})$ and $14 \%(\mathrm{Ca} / \mathrm{Al} / \mathrm{Si} / \mathrm{O})$ that can be related to $\mathrm{C}-\mathrm{S}-\mathrm{H}$, $\mathrm{C}-\mathrm{A}-\mathrm{S}-\mathrm{H}$ and crystalline phases such Heulandite $\left(\mathrm{Ca}_{6} \mathrm{Si}_{26} \mathrm{Al}_{9} \mathrm{O}_{72} \mathrm{At}_{24}\right)$, Lawsonite $\left(\mathrm{Ca}_{4} \mathrm{Al}_{8} \mathrm{Si}_{8} \mathrm{O}_{40} \mathrm{H}_{16}\right)$ and Grossular $\left(\mathrm{Ca}_{24} \mathrm{Al}_{16} \mathrm{Si}_{24} \mathrm{O}_{96}\right)$ as detected via XRD analysis.

BSE image for IP30 after 28 days of curing is shown in Figure 9 A, while the element and phase mapping using EDS is shown in Figure 9B and C, respectively. A decrease in volcanic ash concentration from $50 \%$ to $30 \%$ demonstrated a decrease in traces of magnesium and aluminum, while an increase in calcium and silica was observed from 13 to $22 \%$ for calcium and 21 to $22 \%$ for silica. Due to the increased concentrations of calcium and silica content, seven phases were detected by the EDS mapping that could be related to the C-S-H and C-A-S-H gels phases. 


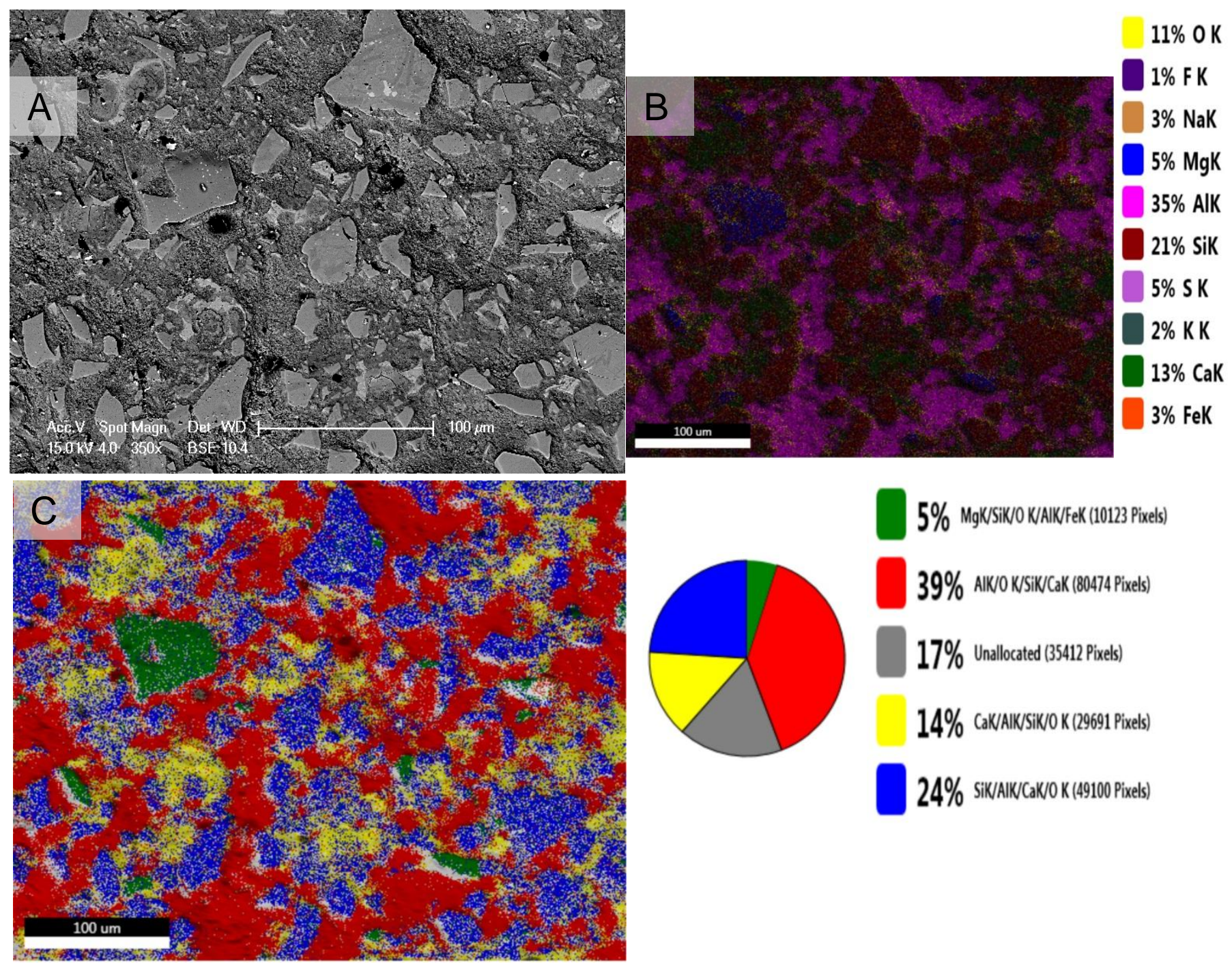

Fig 8. BSE analysis of IP 50 after 28 days of curing A; SEM image, B. Elemental comoposition mapping, C. Phase composition mapping using EDS analysis

Two phases were detected containing magnesium; among them one containing 8\% of $\mathrm{Si} / \mathrm{Al} / \mathrm{Ca} / \mathrm{O}$, while $1 \%$ involving $\mathrm{Fe} / \mathrm{Si} / \mathrm{Ca} / \mathrm{Al} / \mathrm{O} / \mathrm{K} / \mathrm{Mg} / \mathrm{S}$. The phases related to magnesium can be related to amorphous M-S-H phase along with traces of periclase and frosterite, that are crystalline in nature. 

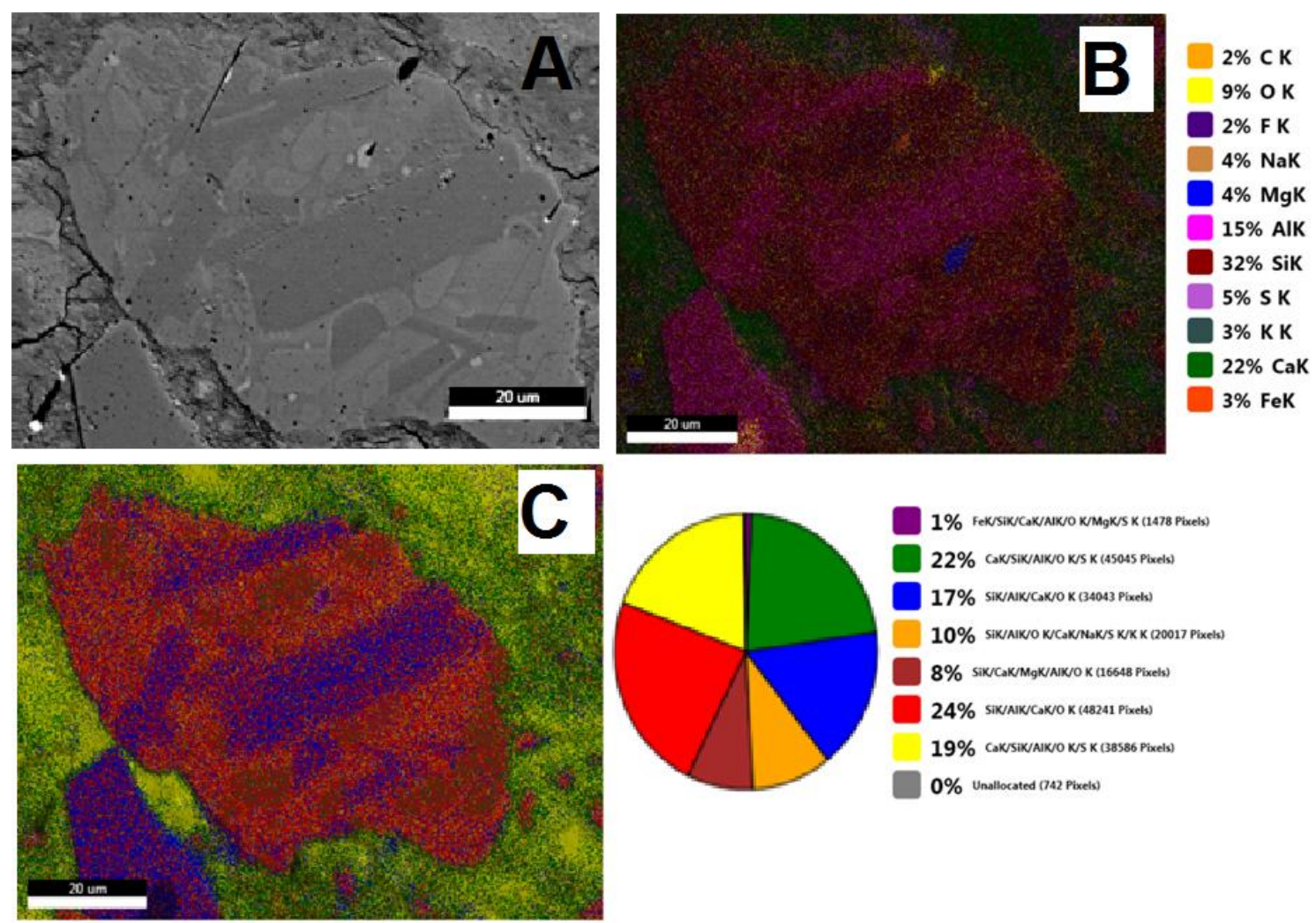

Fig 9 A. BSE micrograph for IP30 after 28 days of curing B. Elemental Mapping using EDS analysis, C. Phase composition mapping using EDS analysis.

The ternary phase of $\mathrm{CaO}-\mathrm{Al}_{2} \mathrm{O}_{3}-\mathrm{SiO}_{2}$ compositional diagram for OPC-VA after 7, 28 and 90 days is shown in Figure 10. Comparing the values from Figure 10 to the literature [37, 38] , three types of C-A-S-H gels were determined describing as low, medium and high calcium C-AS-H gels. 

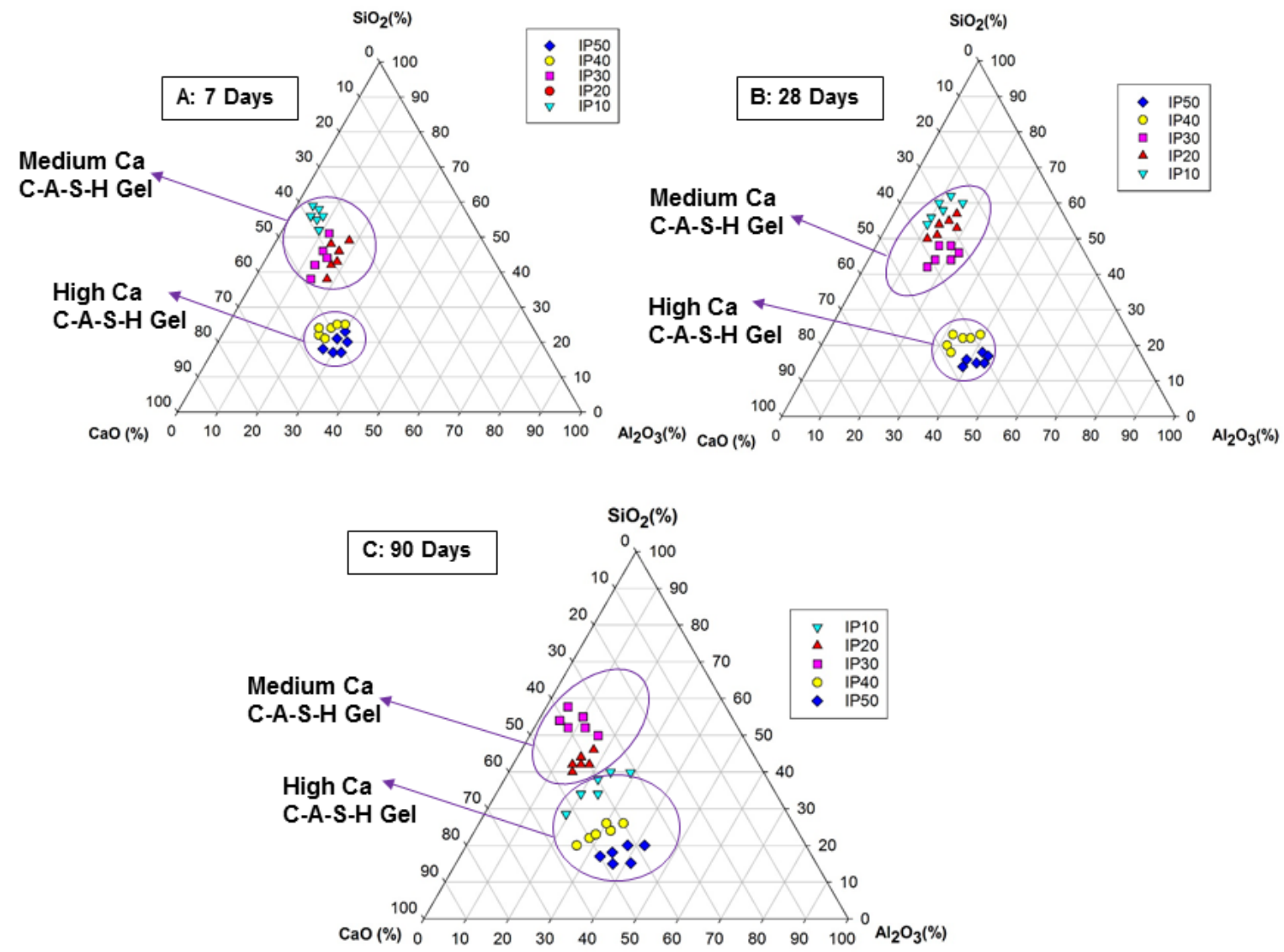

Fig 10. Ternary phase diagram of OPC-VA combinations after 7, 28 and 90 days of curing given by $\mathrm{A}, \mathrm{B}$ and $\mathrm{C}$, respectively

At all ages of hydration, IP40 and IP50 were in the high calcium zone of the C-A-S-H gel; this could be attributed to the higher calcium oxide content from the volcanic ash that may have led to high calcium C-A-S-H gel. Furthermore, some amount of amorphous reaction was also present on the surface of the unreacted volcanic ash crystals that could have led to additional high calcium C-A-S-H zones.

IP10 was in the medium calcium C-A-S-H zone after 28 days of hydration. However, after 90 days of curing IP10 samples exhibited high calcium C-A-S-H which may have been due to partial calcium leaching from the unreacted volcanic ash. As seen in the SEM micrograph (see Figure 7), as curing progressed the zeolite crystal growth on the unreacted ash crystals may have 
expanded, leading to an increase in the nano-porosity of the system. On the contrary, a decrease in calcium content of the C-A-S-H gel for IP30 indicates that medium calcium C-A-S-H gel may contribute to lower porosity, while high calcium C-A-S-H gels led to higher porosity which is significantly dominated by the unreacted volcanic ash crystals which can cause high vesicularity in the cement matrix. These observations are confirmed by nitrogen sorptiometry data which is presented in Section 3.7.

The ternary phase compositional diagram consisting of $\mathrm{CaO}, \mathrm{MgO}$, and $\mathrm{SiO}_{2}$ for $\mathrm{OPC}-\mathrm{VA}$ hardened cement paste after 90 days of curing is shown in Figure 11. IP20, 40 and 50 demonstarted crystalline phases of M-S-H such as diopside an forsterite. These magnesium related crystalline phases were also detected via XRD analysis. Addition of volcanic ash increased the $\mathrm{MgO}$ content in the mix, and greater than $30 \%$ substitution of Portland cement with volcanic ash led to the formation of zeolitic products of magnesium such as dioposide and forsterite. Magnesium related analysis after 90 days of curing was studied since M-S-H usually develops at a later age as compared to the C-S-H phase that develops during the early age of curing [39].

Previous studies have shown that additional existence of magnesium can react with calcium from the C-S-H leading to decalcification of C-S-H forming secondary magnesium related zeolitic products [39]. Furthermore, the addition of volcanic ash increased the calcium, silica, magnesium and alumina content in the mix favoring the formation of magnesium aluminate hydrate (M-A-H) and magnesium silicate hydrate (M-S-H). Brew and Glasser [29] stated that magnesium is partly soluble in C-S-H, and therefore independent phases of $\mathrm{M}-\mathrm{A}-\mathrm{H}$ and $\mathrm{M}-\mathrm{S}-\mathrm{H}$ are formed. M-S-H related phases are immisible with C-S-H phases, thus further studies are required by processing the volcanic ash so that calcium and alumina could alter $\mathrm{M}-\mathrm{S}-\mathrm{H}$ phase or magnesium be incorporated into the $\mathrm{C}-\mathrm{S}-\mathrm{H}$ and $\mathrm{C}-\mathrm{A}-\mathrm{S}-\mathrm{H}$ related phases. The work by Vanderperre et al. [40] on using fly ash with Portland cement for making cement paste could be extended by pulversing the volcanic ash to a smaller particle size, allowing the amorphous part of the silica to react with the brucite $\left(\mathrm{Mg}(\mathrm{OH})_{2}\right.$ forming M-S-H phase. The inclusion of sodium hexametaphosphate (NaHMP) as an additive can improve the uniformity of the cement matrix by enhancing the fluidity of MgO-micro-silica systems [14]. 


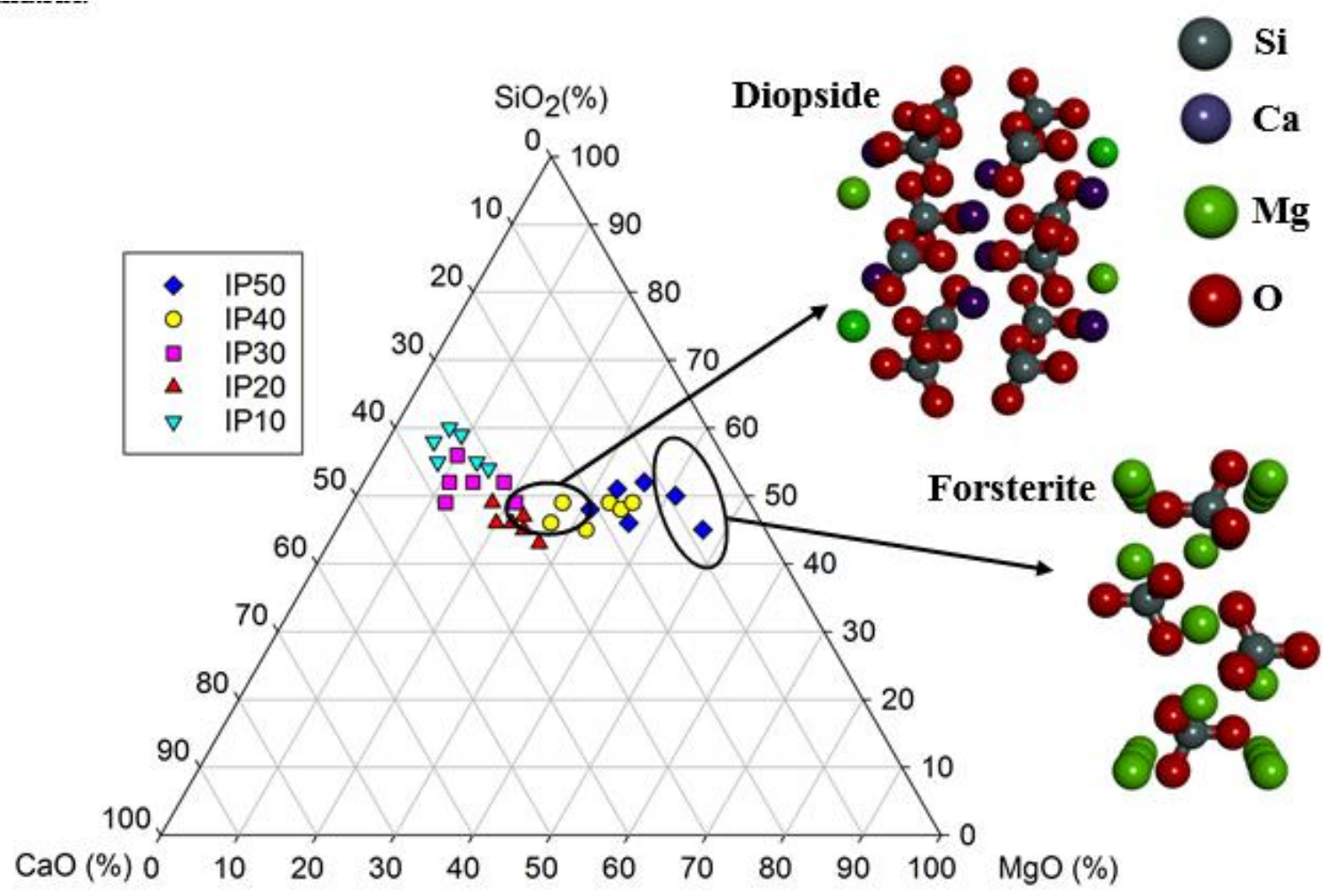

Fig 11. Ternary phase compositional diagram for $\mathrm{CaO}-\mathrm{MgO}-\mathrm{SiO}_{2}$ for $\mathrm{OPC}-\mathrm{VA}$ combinations after 90 days of curing

\subsection{Petrographic Analysis}

Petrography analysis using optical microscope for OPC, IP10, IP40 and IP50 is shown in Figure 12. Unreacted volcanic ash crystals were observed in IP10, IP40 and IP50, with the size of the unreacted volcanic ash crystal increasing with the higher volcanic ash content in the mix. As seen in the SEM studies (Section 3.4), unreacted volcanic ash led to an increase in vesiculary and significantly contributed to increasing the porosity of the overall system. One major aspect was the particle size of the volcanic ash used in this study which had a significant influence on micro and pore structure formation as shown later by nitrogen sorptiometry analysis (Refer to section 3.7). Mean particle size of the volcanic ash was $17.14 \mu \mathrm{m}$ (see Table 3). Reduction of the particle size by additional ball milling of the ash could have led to higher effective substitution, since the 
finer particle size of the volcanic ash would facilitate hydration in the mix by increasing the densification and correspondingly reducing the porosity of the cementitious matrix.
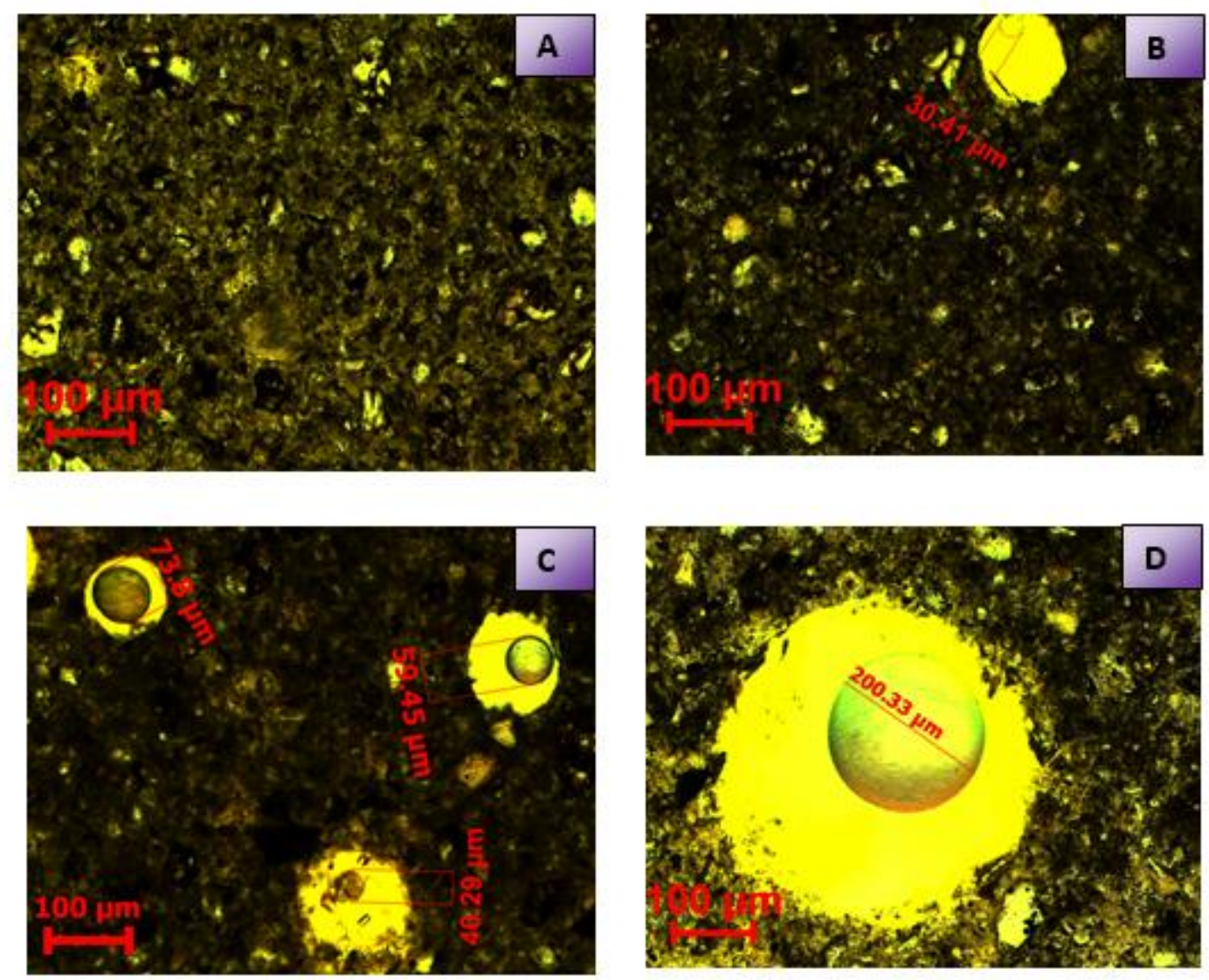

Fig 12. Optical microscopy images for A) OPC, B) IP10, C) IP40 and D) IP50 after 7 days of hydration

Optical microscopy images for specimen IP20 after 90 days of curing is shown in Figure 13. Additional curing for 90 days helped the volcanic ash to develop secondary zeolitic growth. IP40 had higher content of volcanic ash crystals as compared to IP20. Therefore, additional alumina was available on the unreacted volcanic ash (See Figure 14) that may have contributed to complete zeolitic growth along with higher amorphous phase when compared to IP20, where partial zeolitic growth was detected as shown in Figure 12. The XRD results support this 
discussion as a higher amorphous content was formed in the hardened cement paste with increasing volcanic ash content. IP20 showed uniform secondary zeolitic growth with an average length of $\sim 9.5 \mu \mathrm{m}$ and unreacted volcanic ash crystals exhibited a diameter range between 5 and $6 \mu \mathrm{m}$.

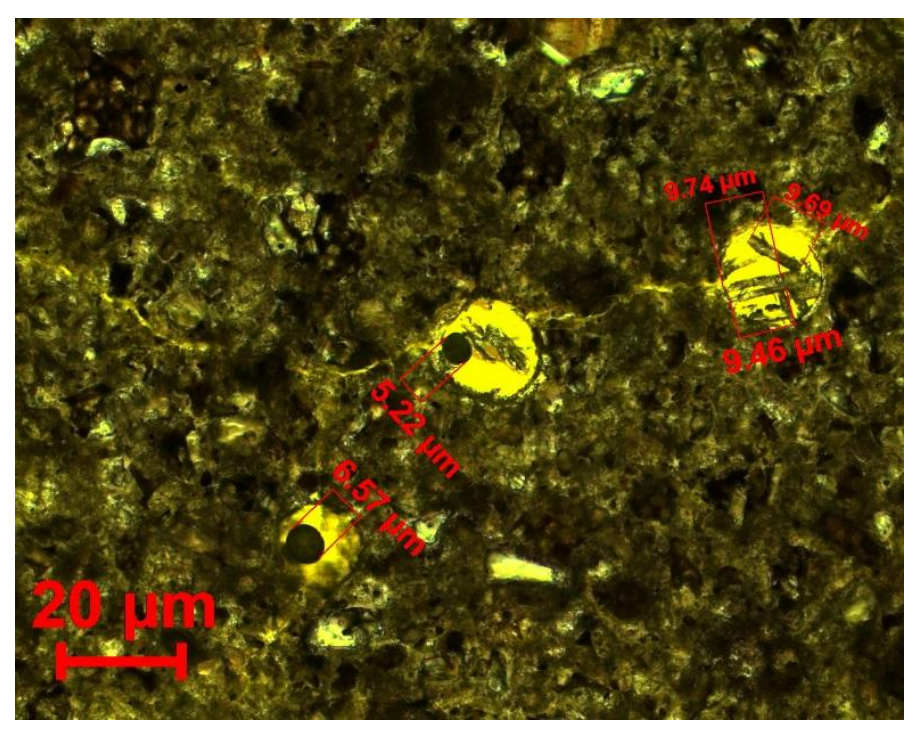

Fig 13. Optical microscopy images for IP20 after 90 days of hydration showing partial secondary pozzolanic growth being observed on the volcanic ash crystals.

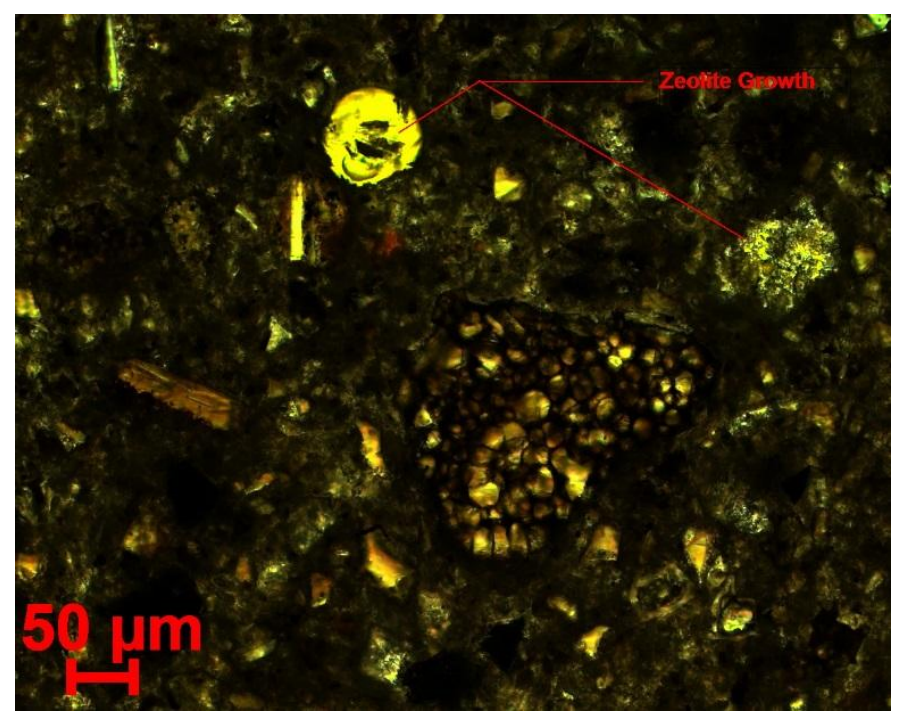

Fig 14. Optical microscopy images for IP40 after 90 days of hydration showing secondary pozzolanic growth being observed on the volcanic ash crystals. 
Previous studies have related the growth of aggolomerated stuctures of these products to M-S-H along with some crystalline products relating to periclase and frosterite, that was also observed by MAS NMR analysis [27, 29]. The unreacted volcanic ash created vesicles and the M-S-H structure is attributed to lower strength phases as compared to C-S-H and C-A-S-H gels [39, 41].

\subsection{X-Ray Photo electron Spectroscopy (XPS)}

XPS analysis of calcium for all the specimens after 7 and 90 days is shown in Figures 15 A and $\mathrm{B}$, respectively. The common peaks associated with XPS of calcium ions are $\mathrm{Ca}^{2+} 2 \mathrm{P}_{3 / 2}$ and $\mathrm{Ca}^{2+}$ $2 \mathrm{P}_{1 / 2}$ which usually occur at $346.8 \mathrm{eV}$ and $350.4 \mathrm{eV}$, exhibiting a spin-orbit spinning value of $\sim 3.6 \mathrm{eV}$ [42]. A decrease in $\mathrm{Ca}^{2+} 2 \mathrm{P}_{3 / 2}$ total atomic percentage (TA\%) values was observed for IP20 and IP50 after 7 and 90 days of curing, while an increase in $\mathrm{Ca}^{2+} 2 \mathrm{P}_{3 / 2}$ values was indicated by IP30 and IP40. A minor change in the values show an increment in the magnesium content, while the binding energy of calcium ions is influenced by $\mathrm{Mg}$ doping predominantly by magnesium based zeolites that are formed due to addition of volcanic ash with Portland cements [43].
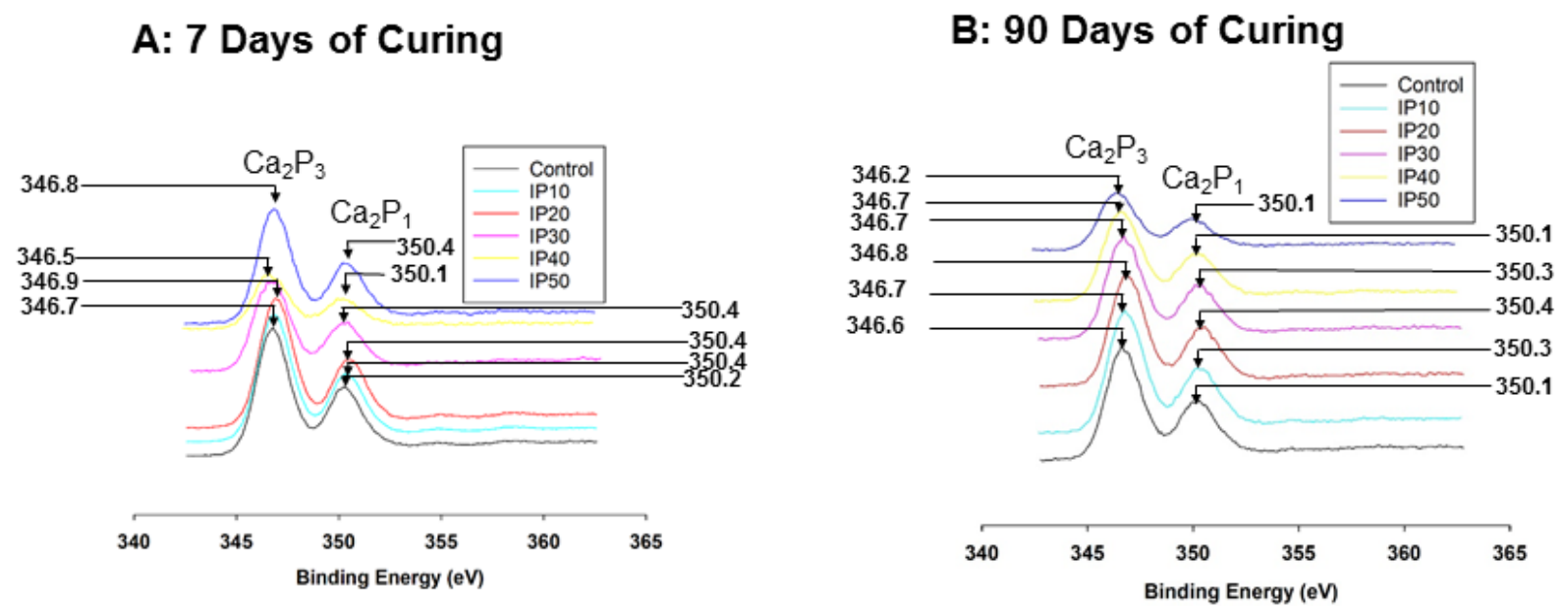

Fig 15. XPS results for calcium for 7 and 90 days. The accuracy of binding energy values is $\pm 0.1 \mathrm{eV}$. 
An increase in binding energy of $\mathrm{Ca}_{2} \mathrm{P}_{3}$ is associated with lower coordination numbers which leads to shorter $\mathrm{Ca}-\mathrm{O}$ bond [44]. This indicates that an increase in binding energy of calcium depleted phases leads to phyllosilicates. Addition of pozzolanic supplementary cementitious materials such as volcanic ash with high $\mathrm{MgO}$ content can cause precipitation and decalcification of C-S-H forming Mg-Si phylliosilicates [13].

XPS results for $\mathrm{Si}^{+4} 2 \mathrm{p}$ after 7 and 90 days of curing is shown in Figure 16. Due to the closely spaced spin-orbit splitting and the amorphosity of the silicon compound, the 2p3/2- 2p1/2 splitting is not observed. Merwinite $\left(\mathrm{Ca}_{3} \mathrm{Mg}\left(\mathrm{SiO}_{4}\right)_{2}\right.$ and Forsterite $\left(\mathrm{Mg}_{2} \mathrm{SiO}_{4}\right)$ can be interpreted at $101.3 \mathrm{eV}$ and $101.6 \mathrm{eV}$, respectively [45]. For Si 2p a decrease in binding energy indicates an increase in calcium content after 90 days of curing. Calcium content acts as a charge balancing cation within the C-S-H structure, meaning that higher residual negative charges are present in the silicate tetrahedral and the lower binding energy is influenced by silicon atoms subjected to higher relaxation [44].

\section{A: 7 Days of Curing}

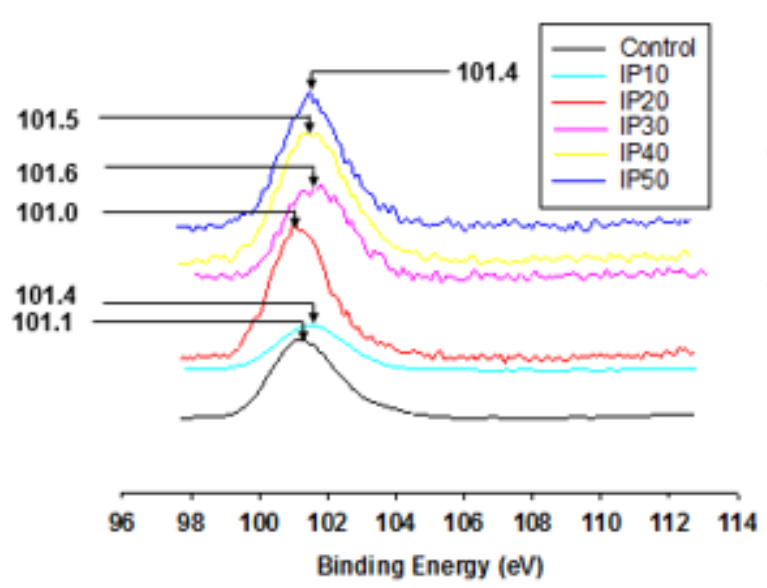

B: 90 Days of Curing

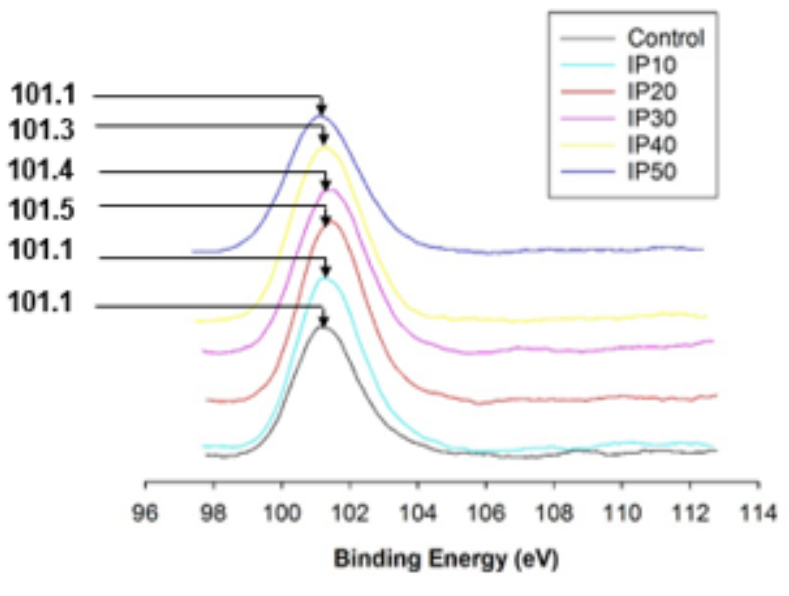

Fig 16. XPS results for $\mathrm{Si}^{+4} 2 p$ for 7 and 90 days. The accuracy of binding energy values is \pm 0.1 $\mathrm{eV}$.

XPS spectra for $\mathrm{Al}^{+3} 2 \mathrm{p}$ and all cement paste combinations after 7 and 90 days of curing is shown in Figure 17. Al behaves similar to $\mathrm{Si}$, with the observed $2 \mathrm{p}$ spin-orbit splitting being relatively small. A NIST database was used to match the binding energy of the XPS peaks to the phases [46]. After 7 days of curing, IP50 and IP20 showed the presence of calcium/sodium- 
alumino-silicate-hydrate at $73.5 \mathrm{eV}$, while IP40 and IP30 showed the presence of gibbsite and natrolite at $73.9 \mathrm{eV}$ and $74.3 \mathrm{eV}$, respectively. Presence of cummingtonite was observed in IP10 at $73.5 \mathrm{eV}$. Cummingtonite is a metamorphic magnesium rich amphibole with a chemical composition of $(\mathrm{Na}, \mathrm{Ca})_{0.5} \mathrm{Fe}_{1.0}\left[\mathrm{Mg}_{1.2} \mathrm{Fe}_{1.5} \mathrm{Al}_{2.3}\right]\left[\mathrm{Si}_{6.8} \mathrm{Al}_{1.2} \mathrm{O}_{22}\right](\mathrm{OH})_{2}$. After 90 days of curing IP50 and IP20 showed the presence of hornblende, while other combinations showed the presence of alkaline earth mineral combining aluminum, iron, magnesium and potassium.

This data suggests that during early stages of curing the zeolitic phases of magnesium, sodium and aluminum are associated with the unreacted volcanic ash. The observation of hornblende in IP20 and IP50 indicates the presence of unreacted volcanic ash. Hornblende's are common constituents of igneous rocks that originate from volcanic eruptions [47]. The detection of hornblende via XPS clearly shows that Mg related phases were observed as remnants that were not involved in the initial hydration process or may be associated with leaching due to long term curing.

\section{A: 7 Days of Curing}

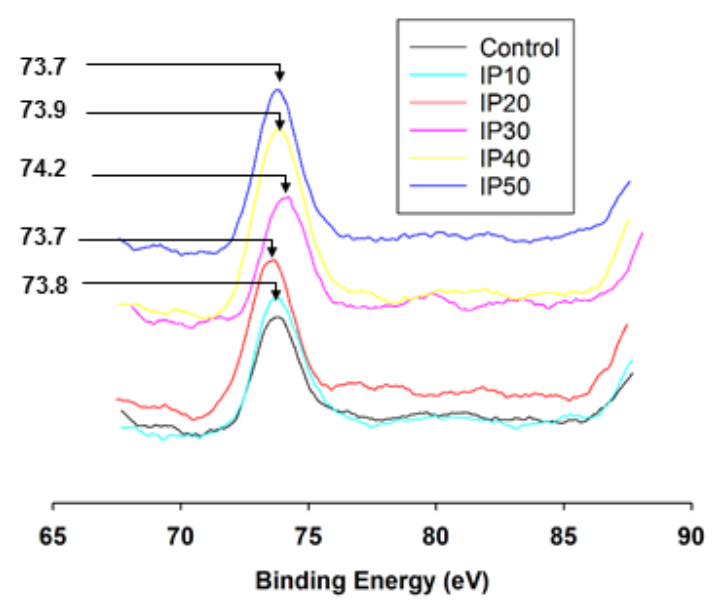

B: 90 Days of Curing

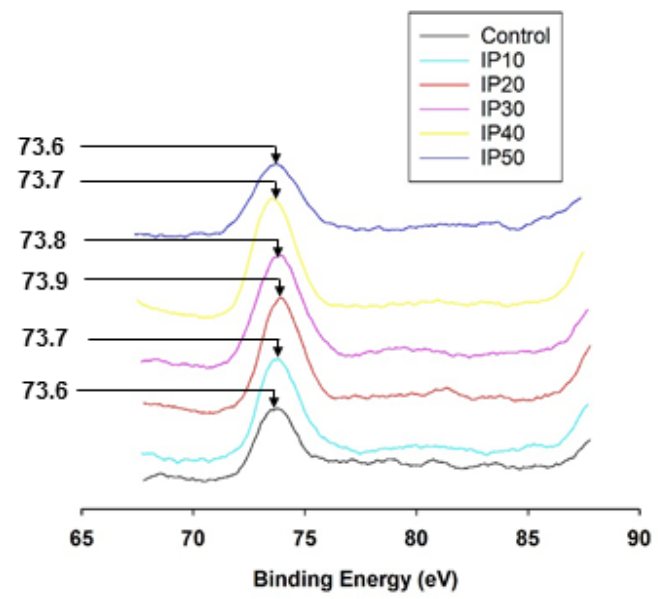

Fig 17. XPS results for $\mathrm{Al}^{+3} 2 \mathrm{p}$ for 7 and 90 days

XPS Spectra for $\mathrm{Mg}^{2+} 1 \mathrm{~s}$ for all the specimens is shown in Figure 18. Addition of volcanic ash caused a clear shift from $1304.3 \mathrm{eV}$ (OPC) to $1304.6 \mathrm{eV}$ (IP10) after 7 days of curing, and from $13055.6 \mathrm{eV}$ (OPC) to $1304.9 \mathrm{eV}$ (IP10) at 90 days of curing. These values indicates the presence of unreacted $\mathrm{Mg}$ related phases of montmorillonite and phlogopite. Montmorillonite ( $\mathrm{Na} / \mathrm{Al} / \mathrm{Mg})$ $\mathrm{Si}_{4} \mathrm{O}_{10}(\mathrm{OH})_{2} \cdot \mathrm{nH}_{2} \mathrm{O}$ belongs to the phyllosilicate group that could be related to $\mathrm{Mg}$ based zeolites 
$[13,48]$. Montmorillonite helps to absorb large numbers of metal cations along with the water molecules on the surface [49]. Phlogopite, commonly known as magnesium mica, was also observed in the specimens prepared with volcanic ash. Phlogopite $(\mathrm{Mg} / \mathrm{Fe}) \cdot 2 \mathrm{SiO}_{4}$ is ususally found in igneous rocks and is related to higher substitutes of magnesium for iron and is a common biotite. Biotite belongs to the phyllosilicate group with sheets consisting of iron, magnesium, aluminum, silicon, oxygen and hydrogen that are loosely bounded to the potassium. Studies show that if phlogopite contains soluble potassium it would influence the alkalinity of the pore solution leading to expansion if deleterious aggregates that are vulnerable to alkali silica reaction (ASR) are used in building concrete structures [8]. Grattan-Bellew and Beaudoin [8] recommended that caution should be excercised when using large volumes of additives belonging to phyllosilicate groups and when used in preparing concretes with aggregates as significant expansion can occur due to ASR reaction.

\section{A: 7 Days of Curing}

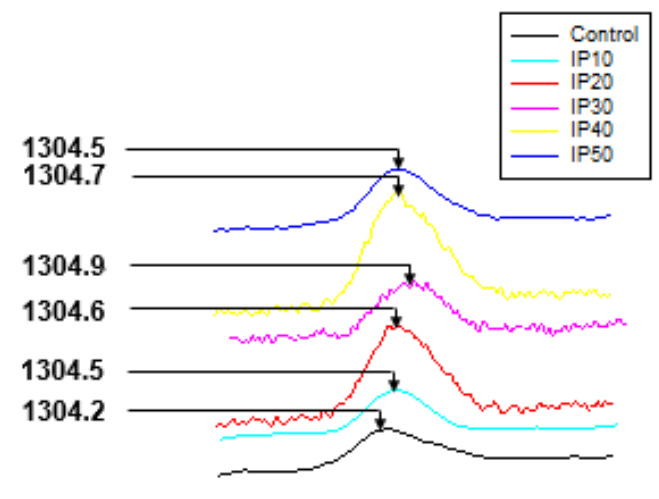

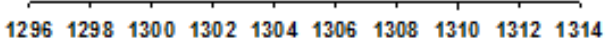

Binding Energy (eV)

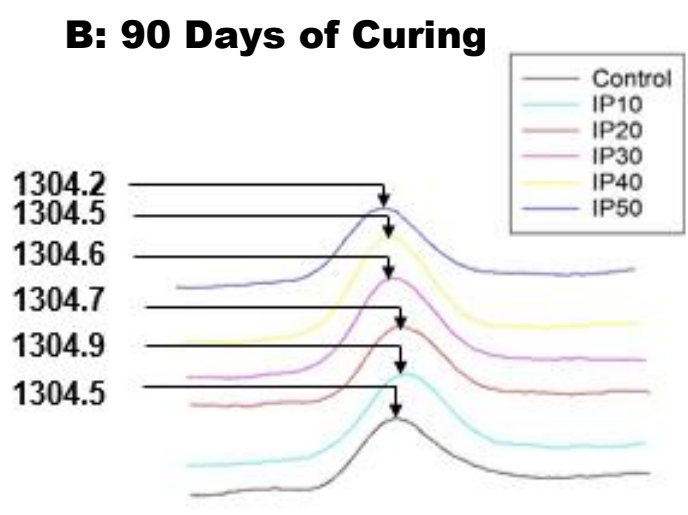

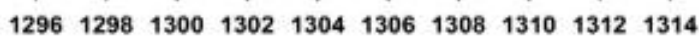
Binding Energy (eV)

Fig 18. XPS results for $\mathrm{Mg}^{2+} 1$ s for 7 and 90 days.

The 90 day cured samples showed a decrease in Si 2p binding energy indicating additional C-S$\mathrm{H}$ formation due to longer curing time. The $\mathrm{Al}^{+3} 2 \mathrm{p}$ and $\mathrm{Mg}^{2+}$ analysis clearly showed the presence of unreacted volcanic ash after 7 days of curing, whereas after longer curing the unreacterd volcanic ash may be involved in forming zeolitic phases of calcium, sodium and magnesium along with the additional M-S-H, C-S-H and C-A-S-H formation. In this study by analyzing the binding energies, we can distinguish different phases providing an insight into the 
silicate structure. XPS data for $\mathrm{Al}^{3+} 2 \mathrm{p}$ and XPS can be a useful tool for characterizing various crystalline phases of calcium silicate hydrates and for further understanding of the composition and structure of the resulting cementitious matrix.

\subsection{Nitrogen Sorptiometry}

The adsorption-desorption isotherms for all specimens after 7,28 and 90 days are shown in Figures 19 A, B and C, respectively. After 7, 28 and 90 days of curing, IP50 showed the highest quantity of nitrogen adsorbed as compared to the rest of the combinations. According to the new classification of adsorption isotherm [50], type II isotherm can exhibit hysteresis (called type IIa). All the samples studied in this work show this type of hysteresis. Type IV is not considered here because in this type one expects the isotherm to level off as the saturation pressure is approached, which is not observed here. The hysteresis of all the samples is of type $\mathrm{H}_{3}$ where the closer point of its loop is expected to be at the saturation point and not before it [50]. Type II isotherm for porous materials indicate that the gas is adsorbed inside the pore initially forming a monolayer, followed by a multilayer and then eventually leading to capillary condensation. 

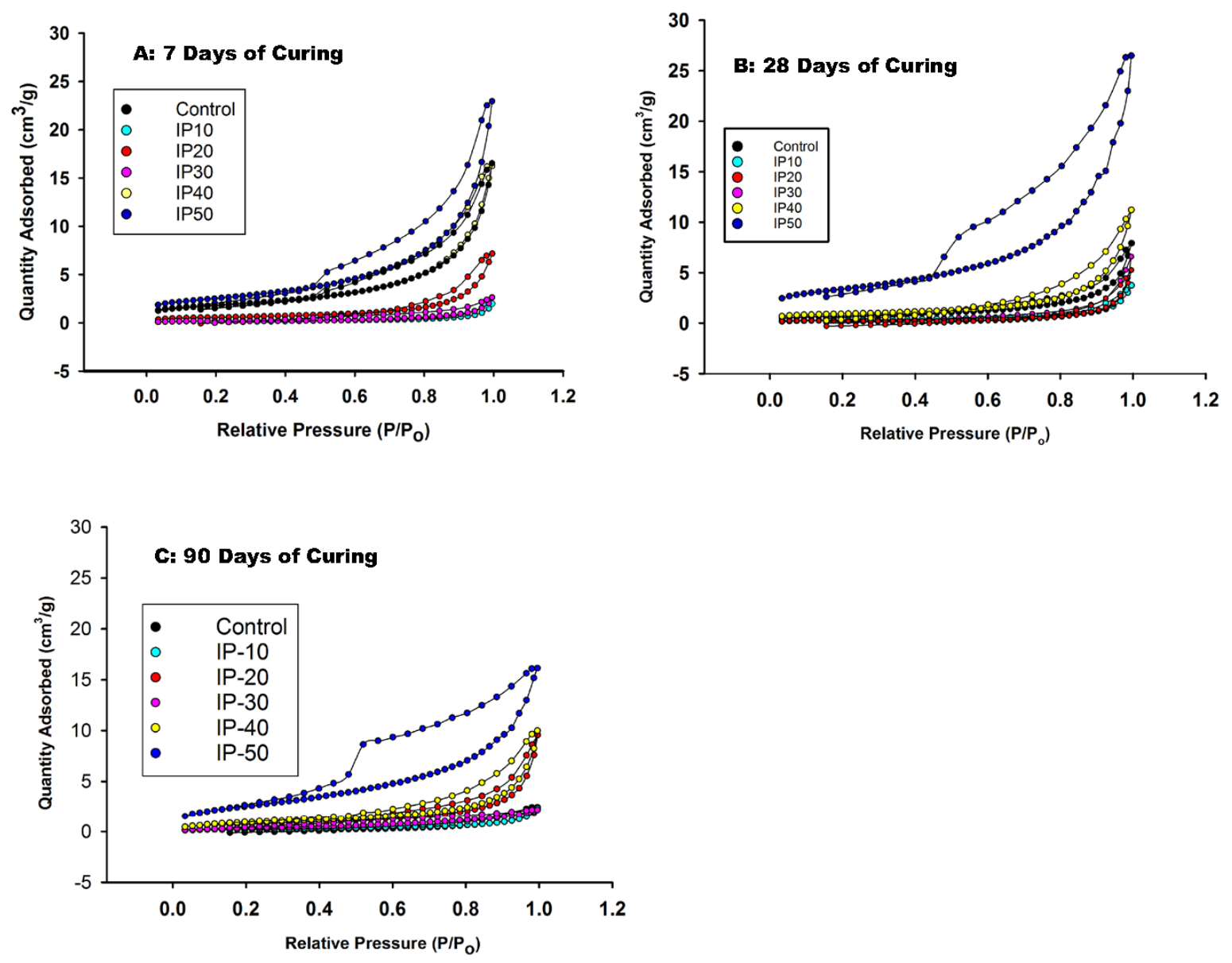

Fig 19. Adsorption-Desorption Isotherms for OPC-Volcanic Ash combinations for 7, 28 and 90 days

At all stages of curing, IP50 clearly showed Type IIa isotherm behavior exhibiting a lower (adsorption) branch obtained by a gradual addition of nitrogen adsorbate followed by progressive withdrawal by upper desorption branch. The hysteresis loop of adsorption and desorption that are observed in multi-range of physiosorption isotherms are associated by gradual loading and emptying of adsorbent by capillary condensation indicating a pore range between 2 and $50 \mathrm{~nm}$ [50].

After 28 days of hydration all specimens excluding IP50 showed $\mathrm{H}_{3}$ hysterisis loop. Also, after 90 days of curing the control (OPC), IP10, IP20, and IP30 exhibited $\mathrm{H}_{3}$ hysteresis loop. IP50 and 
IP40 specimen also demonstrated $\mathrm{H}_{3}$ isotherms, but with clearly higher adsorption capacity which is a direct consequence of the higher porosity. The rest of the specimens showed $\mathrm{H}_{3}$ loop that are commonly attributed to having pores of short slit with a wide body [50].

The cumulative volume of nitrogen intrusion versus pore width for all the specimens after 7, 28 and 90 days is shown in Figure 20. Following 7 days of curing, IP30 showed the least nitrogen volume intrusion $\left(0.001 \mathrm{~cm}^{3} / \mathrm{g}\right)$ followed by IP10, IP20, IP40, control and IP50. At all ages of curing, IP50 showed the highest cumulative volume of intrusion as compared to the rest of the samples.

A: 7 Days of Curing

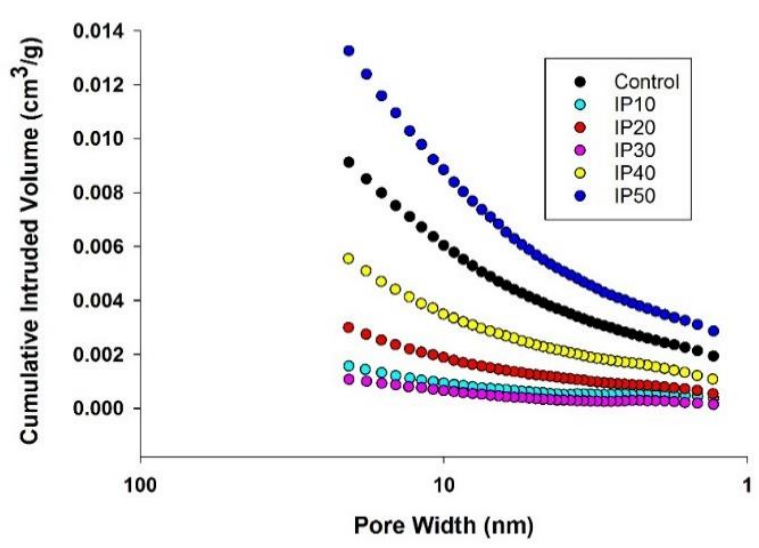

B: 28 Days of Curing

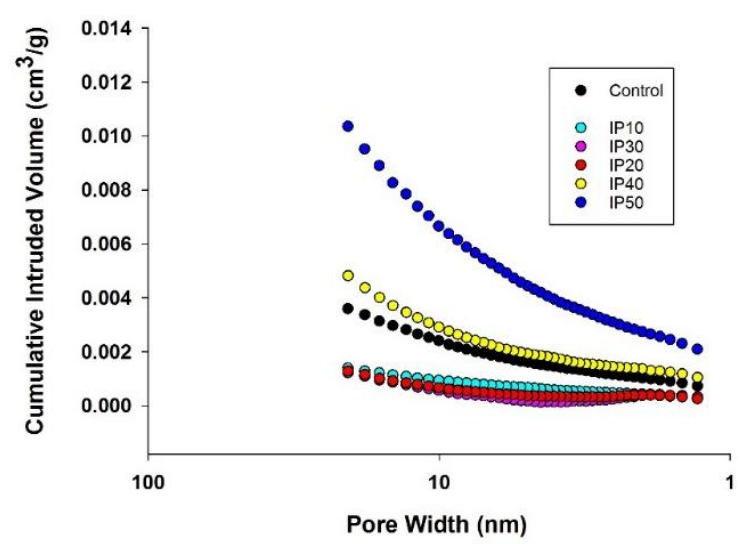

\section{C: 90 Days of Curing}




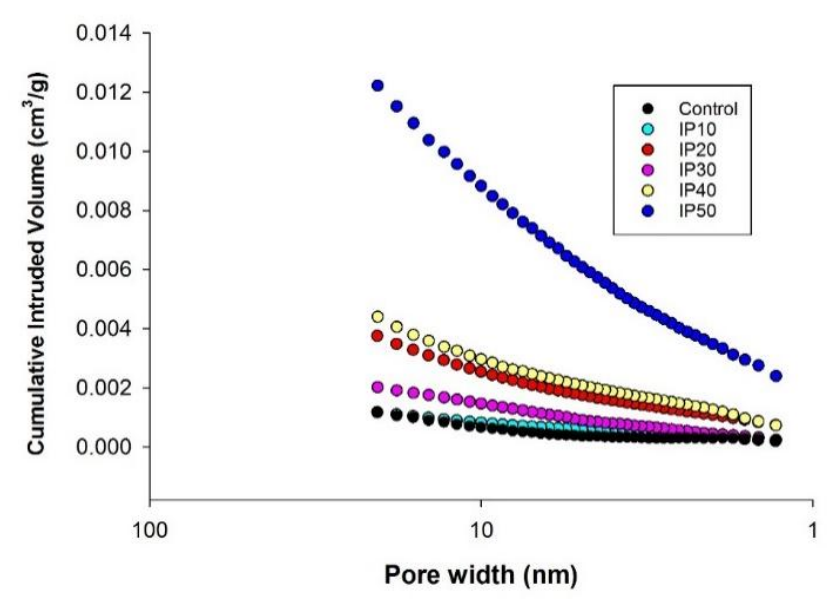

Fig 20. Pore size distribution plots for cumulative intruded volume versus pore width for 7, 28 and 90 days cured samples.

IP50 showed an increase in cumulative volume by a factor of 10 as compared to IP30. After 28 days of curing, the cumulative intruded volume of Portland cement dropped below IP40 indicating densification of the matrix. IP20 showed a reduction in cumulative nitrogen intrusion after 28 days of curing and the cumulative intruded volume dropped from $0.003 \mathrm{~cm}^{3} / \mathrm{g}$ measured after 7 days to $0.001 \mathrm{~cm}^{3} / \mathrm{g}$ after 28 days of curing. After 90 days of curing, an increase in nitrogen intruded volume was observed by IP20 as compared to IP30, IP10 and OPC. In case of IP20, a trend is observed where the volcanic ash content helps to densify the matrix between 7 and 28 days, while an increase in porosity is observed between the period of 28 and 90 days. As expected in OPC, a steady decrease in porosity was observed with the increase in curing time. IP10 had 1.5 times higher cumulative intruded volume compared to IP30 after 7 days of curing; while after 28 days, both had similar cumulative intruded nitrogen volumes, and after 90 days IP10 had twice as less intruded volume compared to IP30.

Brunauer-Emmett-Teller (BET) surface area for control and all combinations is shown in Figure 21. For OPC, an increase in surface area was observed with increase in the curing age. 
Incremental increase in curing from $5.39 \mathrm{~m}^{2} / \mathrm{g}$ after 7 days to $5.82 \mathrm{~m}^{2} / \mathrm{g}$ after 90 days was observed among the Portland cements (controls). Previous studies have attributed the increase in surface area of OPC to the development of microstructural characteristics of C-S-H gels [51-53]. For the volcanic ash-OPC blends, an increase in surface area was observed for IP10, IP20, IP30, while a reverse trend was observed for IP40 and IP50. A decrease in surface area was observed for IP40 after 28 days of hydration from $3.9 \mathrm{~m}^{2} / \mathrm{g}$ to $3.24 \mathrm{~m}^{2} / \mathrm{g}$, while after 90 days an abrupt decrease from $11.96 \mathrm{~m}^{2} / \mathrm{g}$ to $9.41 \mathrm{~m}^{2} / \mathrm{g}$ was observed for IP50. Decrease in surface area for greater than 30\% volcanic ash substitution to Portland cement suggests that not all of the volcanic ash is getting involved in the hydration process. This also indicates that the concentration of substitution of volcanic ash has substantial effect on microstructure by forming hydration products in various length scales and morphology. This intermittent and irregular morphology of the hydration products and unreacted volcanic ash could influence the surface area of the resulting cementitious matrix. Bordor et al. [54] attributed the decrease in the pore surface area with the increase in hydration to the forming of ink bottle pores with narrow necks. As the hydration progresses the large deposits of hydration products develop at the entrance of the pores, leading to excess crowding at the pore necks and resulting in constricted pore entrances. 


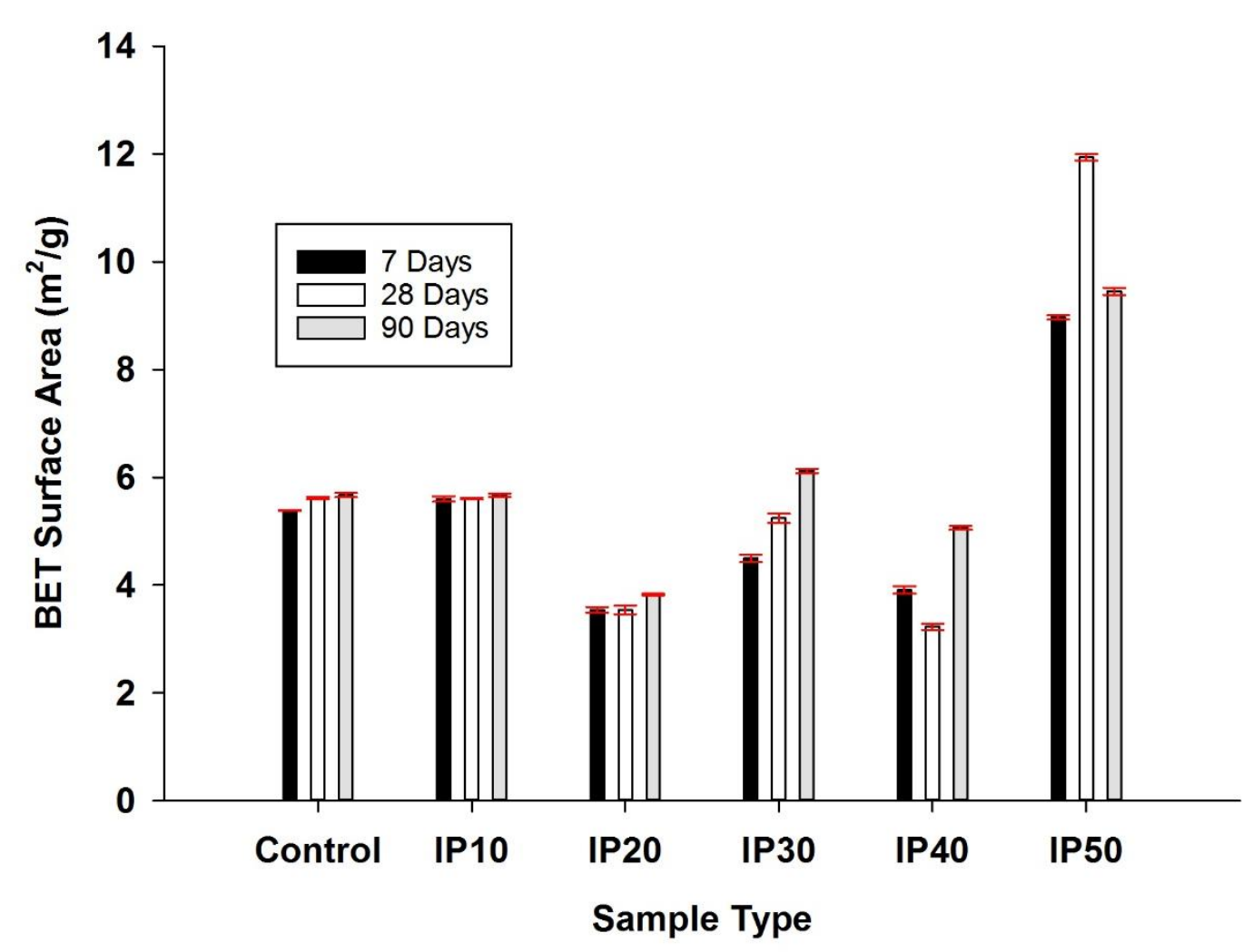

Fig 21. BET Surface area for the control (OPC) and OPC-VA combinations

As shown by NMR, XRD, XPS and SEM/EDS analysis, the blend of volcanic ash and Portland cements produced C-A-S-H, M-S-H, C-S-H along with several other crystalline phase. The decrease in surface area for volcanic ash cement combinations could be attributed to the formation of several hydration products along with remnants of unreacted volcanic ash that may led to jamming effect at the pore necks. This work shows that substitution of volcanic ash greater than $30 \%$ can lead to a decrease in surface area caused by jamming of the hydration products that lead to increase in pore sizes and formed higher pores systems.

Bulk and surface characterization techniques were used towards understanding the microstructural product formation from the volcanic ash/OPC combination that can be used towards predicting an optimum mix design (see Table 9). The optimum mix design may consider the age of curing, particle size of the volcanic ash and the resulting microstructural products that affect the porosity of the resulting cementitious matrix. Additional future work is required using advanced beam line techniques including quasi elastic neutron scattering, small angle neutron/X- 
ray scattering and micro/nano tomorgraphy to have an insight into the resulting microsctructure that relate it to water dynamics to the exact surface area, particle size distribution and polydispersity of the resulting microstructure products in cement based systems.

Table 9. Summary of micro-pore structural characterization towards an optimum mix design for this work

\begin{tabular}{|c|c|c|}
\hline \multirow{2}{*}{$\begin{array}{c}\text { Characterization } \\
\text { Technique }\end{array}$} & \multicolumn{2}{|c|}{ Summary of Microstructural Product Formation } \\
\hline & Advantages & Drawbacks \\
\hline $\begin{array}{l}\text { Qualitative and Semi- } \\
\text { quantitative XRD }\end{array}$ & $\begin{array}{l}\text { Phases related to C-S-H and C-A-S- } \\
\text { H were observed among the } \\
\text { volcanic ash substituted } \\
\text { combination. } \\
\text { - Amorphous content increased in } \\
\text { hardened cements with the increase } \\
\text { volcanic ash content in the mix. }\end{array}$ & $\begin{array}{l}\text { Phases related to } \mathrm{MgO} \text { and } \mathrm{M}-\mathrm{A}-\mathrm{S}-\mathrm{H} \\
\text { content phase was observed among } \\
\text { the volcanic ash/OPC combinations } \\
\text { (IP 30, IP40 and IP50) }\end{array}$ \\
\hline $\begin{array}{l}{ }^{29} \text { Si Magic Angle } \\
\text { Spinning (MAS) } \\
\text { Nuclear Magnetic } \\
\text { Spectroscopy (NMR) }\end{array}$ & $\begin{array}{l}\text { Increase in curing period }(>28 \\
\text { days) lead to an increase in } \mathrm{Q}^{\circ} \text { and } \\
\mathrm{Q}^{1} \text {, while gradual reduction in } \\
\mathrm{Q}^{3}(1 \mathrm{Al}) \text { and } \mathrm{Q}^{4}(1 \mathrm{Al}) \text { is associated } \\
\text { to C-N-A-S-H gel structure among } \\
\text { IP-40 and IP-50 combinations. }\end{array}$ & $\begin{array}{l}\text { At early age ( } 7 \text { days) IP40 and } 50 \\
\text { showed presence of phases Mg } \\
\text { related zeolitic phases as curing } \\
\text { during increased due to high } \\
\text { availability of } \mathrm{Mg}, \mathrm{Al} \text {, and } \mathrm{Si} \text { from } \\
\text { the volcanic ash. }\end{array}$ \\
\hline $\begin{array}{l}\text { Scanning Electron } \\
\text { Microscopy (SEM), } \\
\text { Optical microscopy, } \\
\text { Energy Dispersive } \\
\text { Spectra (EDS) }\end{array}$ & $\begin{array}{l}\text { BSE/EDS analysis showed that IP40 } \\
\text { and IP50 were in high calcium C-A- } \\
\text { S-H gel zones. Decrease in volcanic } \\
\text { ash content lead to low C-A-S-H gel } \\
\text { for IP-30 indicated, which may have } \\
\text { contributed to lower porosity. }\end{array}$ & $\begin{array}{l}\text { Addition of volcanic ash increased } \\
\text { the MgO content in the mix, } \\
\text { indicating greater than } 30 \% \\
\text { substitution of OPC with VA lead to } \\
\text { magnesium below } 30 \% \text { volcanic ash } \\
\text { substitution based on zeolitic } \\
\text { products such as dioposide and } \\
\text { forsterite. }\end{array}$ \\
\hline $\begin{array}{l}\text { X-Ray Photoelectron } \\
\text { Spectroscopy (XPS) }\end{array}$ & $\begin{array}{l}\text { Decrease in Si } 2 \mathrm{p} \text { binding energy } \\
\text { was observed due to additional } \\
\text { curing ( } 90 \text { days) indicating } \\
\text { additional C-S-H formation. } \\
\text { A shift in } \mathrm{Si} 2 \mathrm{p} \text { binding energy } \\
\text { from } 101.0 \mathrm{eV} \text { (IP30) to } 101.5 \\
\text { (IP40) and } 101.6 \text { (IP50) samples } \\
\text { were observed after } 7 \text { days } \\
\text { indicating alumina effect on C-S- } \\
\text { H. }\end{array}$ & 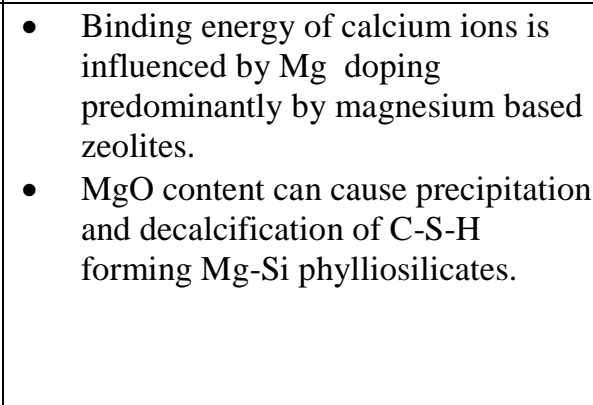 \\
\hline $\mathrm{N}_{2}$ sorptiometry & $\begin{array}{l}\text { IP10 had the least intruded pore } \\
\text { volume after } 28 \text { and } 90 \text { days of } \\
\text { curing, while IP30 showed the least } \\
\text { nitrogen intrusion after } 7 \text { days of } \\
\text { curing. } \\
\text { At different age of curing different } \\
\text { volcanic ash/OPc combination } \\
\text { needs to be selected to tailor } \\
\text { specific applications. }\end{array}$ & $\begin{array}{l}\text { At all ages IP50 had the highest } \\
\text { quantiy of nitrogen adsorbed } \\
\text { compared to the rest of the } \\
\text { specimens. } \\
\text { Greater than } 30 \% \text { substitution of } \\
\text { OPC with volcanic ash leads to } \\
\text { decrease in surface area and lead to } \\
\text { larger sized pores. }\end{array}$ \\
\hline
\end{tabular}




\section{Conclusion}

This work provides an insight into effective substitution of volcanic ash to Portland cement by considering micro and pore structural developments at different stages of curing. An experimental study was undertaken to examine the pore and microstructure of hardened cement pastes prepared with natural pozzolanic volcanic ash and OPC. The specimens were cured for 7 , 28 and 90 days. The micro and pore structure analysis included XRD, SEM/BSE with EDS analysis, optical microscopy, MAS NMR, XPS and nitrogen adsorption. From our analysis we find the following:

- $\mathrm{C}-\mathrm{S}-\mathrm{H}, \mathrm{C}-\mathrm{A}-\mathrm{S}-\mathrm{H}$ and $\mathrm{M}-\mathrm{S}-\mathrm{H}$ along with the other crystalline products were detected as the main hydration products for the cement pastes prepared with volcanic ash and Portland cement.

- Greater than $30 \%$ substitution of Portland cement with volcanic ash led to increased porosity and vesicularity in the cementitious matrix system compared to OPC control samples. SEM and Optical microscopy clearly showed the presence of unreacted volcanic ash even after 28 days of curing, while XRD analysis showed higher amounts of Mg-related phases for greater than 30\% subsitituion of Portland cement with volcanic ash.

- XPS analysis showed the presence of unreacted $\mathrm{Mg}$ related zeolitic phases of montmorillonite and phlogopite in the cured cement paste. These phases are usually present in the base volcanic ash.

- $\mathrm{XRD}, \mathrm{BSE} / \mathrm{EDS}$, and MAS NMR analysis showed the presence of forsterite, periclase and diopside that are related to magnesium based phases. Addition of volcanic ash lead to 
the formation of $\mathrm{M}-\mathrm{S}-\mathrm{H}$ and related crystalline phases that were attributed to lower strength phase as compared to C-S-H and C-A-S-H gels.

- Nitrogen adsorption results showed that substitution of volcanic ash greater than $30 \%$ lead to decrease in surface area that was influenced by jamming of the hydration products near the vicinity of the pore necks leading to increase in pore sizes.

\section{Acknowledgement}

We acknowledge "Kuwait Foundation for the Advancement of Sciences" and "Kuwait-MIT Center for Natural Resources and the Environment" for the support during this work. This work made use of the Center for Material Science and Engineering (CMSE) shared experimental facilities at MIT, supported by the National Science Foundation under award number DMR-0819762. We thank Dr. Charlie Settens, Timothy McClure, and Patrick Boisvert from the Center for Material Science and Engineering for their help in collecting data using XRD, Optical microscopy and SEM, respectively. In addition, we acknowledge the support of the research administration of Kuwait University Project Nos. GS 01/01, GS 01/03 and GS02/08 and the Nanoscopy Science Center. The second author (Anfal Al-Aibani) expresses her appreciation to the Faculty of Graduate Studies, Kuwait University, Kuwait. We also express our gratitude to Badria Ali Reda and Sudeep Joshep for their assistance in NMR, and nitrogen adsorption experiments, respectively.

\section{References}

[1] Jackson M, Vola G, V̌̌ianský D, Oleson J, Scheetz B, Brandon C, et al. Cement Microstructures and Durability in Ancient Roman Seawater Concretes. In: Válek J, Hughes JJ, Groot CJWP, editors. Historic Mortars: Springer Netherlands; 2012. p. 49-76.

[2] Gotti E, Oleson J, Bottalico L, Brandon C, Cucitore R, Hohlfelder R. A comparison of the chemical and engineering characteristics of ancient roman hydraulic concrete with a modern reproduction of vitruvian hydraulic concrete*. Archaeometry. 2008;50(4):576-90. 
[3] Milia A, Mirabile L, Torrente M, Dvorak J. Volcanism offshore of Vesuvius volcano in Naples Bay. Bulletin of Volcanology. 1998;59(6):404-13.

[4] Odler I. Special Inorganic Cements: Taylor \& Francis; 2003.

[5] Kurdowski W. Cement and Concrete Chemistry: Springer London, Limited; 2014.

[6] Taylor HFW. Cement Chemistry, Second Edition: Thomas Telford; 1997.

[7] Chester AW, Derouane EG. Zeolite Characterization and Catalysis: A Tutorial: Springer Netherlands; 2009.

[8] Grattan-Bellew PE, Beaudoin JJ. Effect of phlogopite mica on alkali-aggregate expansion in concrete. Cement and Concrete Research. 1980;10(6):789-97.

[9] Kupwade-Patil K, Allouche E. Impact of Alkali Silica Reaction on Fly Ash-Based Geopolymer Concrete. Journal of Materials in Civil Engineering. 2013;25(1):131-9.

[10] ASTM. ASTM 305-14Standard Practice for Mechanical Mixing of Hydraulic Cement Pastes and Mortars of Plastic Consistency. ASTM C305-14. West Conshohocken: ASTM International; 2003.

[11] ASTM. Standard Specification for Coal Fly Ash and Raw or Calcined Natural Pozzolan for Use in Concrete. ASTM C 618-12a. West Conshohocken: ASTM International; 2004.

[12] Celik K, Jackson MD, Mancio M, Meral C, Emwas AH, Mehta PK, et al. High-volume natural volcanic pozzolan and limestone powder as partial replacements for portland cement in self-compacting and sustainable concrete. Cement and Concrete Composites. 2014;45(0):136-47.

[13] Roosz C, Grangeon S, Blanc P, Montouillout V, Lothenbach B, Henocq P, et al. Crystal structure of magnesium silicate hydrates (M-S-H): The relation with 2:1 Mg-Si phyllosilicates. Cement and Concrete Research. 2015;73(0):228-37.

[14] Zhang T, Vandeperre $\mathrm{L}$, Cheeseman CR. Formation of magnesium silicate hydrate (M-S-H) cement pastes using sodium hexametaphosphate. Cement and Concrete Research. 2014;65(0):8-14.

[15] Myers RJ, Bernal SA, San Nicolas R, Provis JL. Generalized Structural Description of Calcium-Sodium Aluminosilicate Hydrate Gels: The Cross-Linked Substituted Tobermorite Model. Langmuir.

2013;29(17):5294-306.

[16] Bernal SA, Provis JL, Walkley B, San Nicolas R, Gehman JD, Brice DG, et al. Gel nanostructure in alkali-activated binders based on slag and fly ash, and effects of accelerated carbonation. Cement and Concrete Research. 2013;53(0):127-44.

[17] Hossain KMA, Lachemi M. Performance of volcanic ash and pumice based blended cement concrete in mixed sulfate environment. Cement and Concrete Research. 2006;36(6):1123-33.

[18] Ramachandran VS, Beaudoin JJ. Handbook of Analytical Techniques in Concrete Science and Technology: Principles, Techniques and Applications: Elsevier Science; 2000.

[19] Andersen MD, Jakobsen HJ, Skibsted J. Characterization of white Portland cement hydration and the $\mathrm{C}-\mathrm{S}-\mathrm{H}$ structure in the presence of sodium aluminate by 27AI and 29Si MAS NMR spectroscopy. Cement and Concrete Research. 2004;34(5):857-68.

[20] Puertas F, Fernández-Jiménez A. Mineralogical and microstructural characterisation of alkaliactivated fly ash/slag pastes. Cement and Concrete Composites. 2003;25(3):287-92.

[21] Palomo Á, Alonso S, Fernandez-Jiménez A, Sobrados I, Sanz J. Alkaline Activation of Fly Ashes: NMR Study of the Reaction Products. Journal of the American Ceramic Society. 2004;87(6):1141-5.

[22] Myers RJ, Bernal SA, Gehman JD, van Deventer JSJ, Provis JL. The Role of Al in Cross-Linking of Alkali-Activated Slag Cements. Journal of the American Ceramic Society. 2015;98(3):996-1004.

[23] Myers RJ, Bernal SA, Provis JL. A thermodynamic model for C-(N-)A-S-H gel: CNASH_ss. Derivation and validation. Cement and Concrete Research. 2014;66(0):27-47.

[24] Richardson IG, Brough AR, Brydson R, Groves GW, Dobson CM. Location of Aluminum in Substituted Calcium Silicate Hydrate (C-S-H) Gels as Determined by 29Si and 27AI NMR and EELS. Journal of the American Ceramic Society. 1993;76(9):2285-8. 
[25] Brydson R, Richardson IG, McComb DW, Groves GW. Parallel electron energy loss spectroscopy study of al-substituted calcium silicate hydrate (C-S-H) phases present in hardened cement pastes. Solid State Communications. 1993;88(2):183-7.

[26] Pardal X, Brunet F, Charpentier T, Pochard I, Nonat A. 27AI and 29Si Solid-State NMR Characterization of Calcium-Aluminosilicate-Hydrate. Inorganic Chemistry. 2012;51(3):1827-36.

[27] MacKenzie KJD, Smith E. Multinuclear Solid-State Nuclear Magnetic Resonance of Inorganic Materials: Elsevier Science; 2002.

[28] Phillips BL, Burnley PC, Worminghaus K, Navrotsky A. 29Si and 1H NMR spectroscopy of highpressure hydrous magnesium silicates. Phys Chem Min. 1997;24(3):179-90.

[29] Brew DRM, Glasser FP. Synthesis and characterisation of magnesium silicate hydrate gels. Cement and Concrete Research. 2005;35(1):85-98.

[30] Novak GA, Colville AA. Efflorescent mineral assemblages associated with cracked and degraded residential concrete foundations in Southern California. Cement and Concrete Research. 1989;19(1):1-6. [31] Liebig E, Althaus E. Pozzolanic Activity of Volcanic Tuff and Suevite: Effects of Calcination. Cement and Concrete Research. 1998;28(4):567-75.

[32] Mertens G, Snellings R, Van Balen K, Bicer-Simsir B, Verlooy P, Elsen J. Pozzolanic reactions of common natural zeolites with lime and parameters affecting their reactivity. Cement and Concrete Research. 2009;39(3):233-40.

[33] Snellings R, Mertens G, Cizer Ö, Elsen J. Early age hydration and pozzolanic reaction in natural zeolite blended cements: Reaction kinetics and products by in situ synchrotron X-ray powder diffraction. Cement and Concrete Research. 2010;40(12):1704-13.

[34] Provis JL, Lukey GC, van Deventer JSJ. Do Geopolymers Actually Contain Nanocrystalline Zeolites? A Reexamination of Existing Results. Chemistry of Materials. 2005;17(12):3075-85.

[35] Kupwade-Patil K, Allouche EN, Islam MR, Gunasekaran A. Encapsulation of solid waste incinerator ash in geopolymer concretes and its applications. ACI Materials Journal. 2014;111(6):691-700.

[36] Hu HC, Lee TY. Synthesis kinetics of zeolite A. Industrial \& Engineering Chemistry Research. 1990;29(5):749-54.

[37] García-Lodeiro I, Fernández-Jiménez A, Palomo A. Variation in hybrid cements over time. Alkaline activation of fly ash-portland cement blends. Cement and Concrete Research. 2013;52(0):112-22.

[38] Garcia-Lodeiro I, Palomo A, Fernández-Jiménez A, Macphee DE. Compatibility studies between N-A$\mathrm{S}-\mathrm{H}$ and $\mathrm{C}-\mathrm{A}-\mathrm{S}-\mathrm{H}$ gels. Study in the ternary diagram Na2O-CaO-Al2O3-SiO2-H2O. Cement and Concrete Research. 2011;41(9):923-31.

[39] Bonen D. Composition and Appearance of Magnesium Silicate Hydrate and Its Relation to Deterioration of Cement-Based Materials. Journal of the American Ceramic Society. 1992;75(10):2904-6. [40] Vandeperre L, Liska M, Al-Tabbaa A. Microstructures of reactive magnesia cement blends. Cement and Concrete Composites. 2008;30(8):706-14.

[41] Bakharev T. Durability of geopolymer materials in sodium and magnesium sulfate solutions. Cement and Concrete Research. 2005;35(6):1233-46.

[42] McWhinney HG, Cocke DL, Balke K, Dale Ortego J. An investigation of mercury solidification and stabilization in portland cement using $X$-ray photoelectron spectroscopy and energy dispersive spectroscopy. Cement and Concrete Research. 1990;20(1):79-91.

[43] Yu T, Ye J, Zhang M. Effect of Magnesium Doping on Hydration Morphology and Mechanical Property of Calcium Phosphate Cement Under Non-Calcined Synthesis Condition. Journal of the American Ceramic Society. 2013;96(6):1944-50.

[44] Black L, Garbev K, Stemmermann P, Hallam KR, Allen GC. Characterisation of crystalline C-S-H phases by X-ray photoelectron spectroscopy. Cement and Concrete Research. 2003;33(6):899-911. 
[45] Okada K, Kameshima Y, Yasumori A. Chemical Shifts of Silicon X-ray Photoelectron Spectra by Polymerization Structures of Silicates. Journal of the American Ceramic Society. 1998;81(7):1970-2. [46] Alexander V. Naumkin AK-V, Stephen W. Gaarenstroom, and Cedric J. Powell. NIST X-ray Photoelectron Spectroscopy Database National Institute of Standards and Technology; 2000.

[47] Irwin WP, Snoke AW, Barnes CG. Geological Studies in the Klamath Mountains Province, California and Oregon: A Volume in Honor of William P. Irwin: Geological Society of America; 2006.

[48] Wollast R, Mackenzie FT, Bricker OP. Experimental precipitation and genesis of sepiolite at earthsurface conditions. American Mineralogist. 1968;53(9-10):1645-62.

[49] Macdonald GA, Abbott AT, Peterson FL. Volcanoes in the Sea: The Geology of Hawaii: University of Hawaii Press; 1983.

[50] Rouquerol J, Rouquerol F, Llewellyn P, Maurin G, Sing KSW. Adsorption by Powders and Porous Solids: Principles, Methodology and Applications: Elsevier Science; 2013.

[51] Blaine R, Valis H. Surface available to nitrogen in hydrated portland cements. Journal of Research of the National Bureau of Standards. 1949;42(3):257-67.

[52] Odler I, Chen Y. Investigations on the aging of hydrated tricalcium silicate and portland cement pastes. Cement and Concrete Research. 1995;25(5):919-23.

[53] Garci Juenger MC, Jennings HM. The use of nitrogen adsorption to assess the microstructure of cement paste. Cement and Concrete Research. 2001;31(6):883-92.

[54] Bodor EE, Skalny J, Brunauer S, Hagymassy Jr J, Yudenfreund M. Pore structures of hydrated calcium silicates and portland cements by nitrogen adsorption. Journal of Colloid and Interface Science.

1970;34(4):560-70. 
Characterization Techniques used to examine the Microscopy, Composition, and Pore Structure of Cementitious Matrix prepared with Volcanic Ash and Ordinary Portland cement

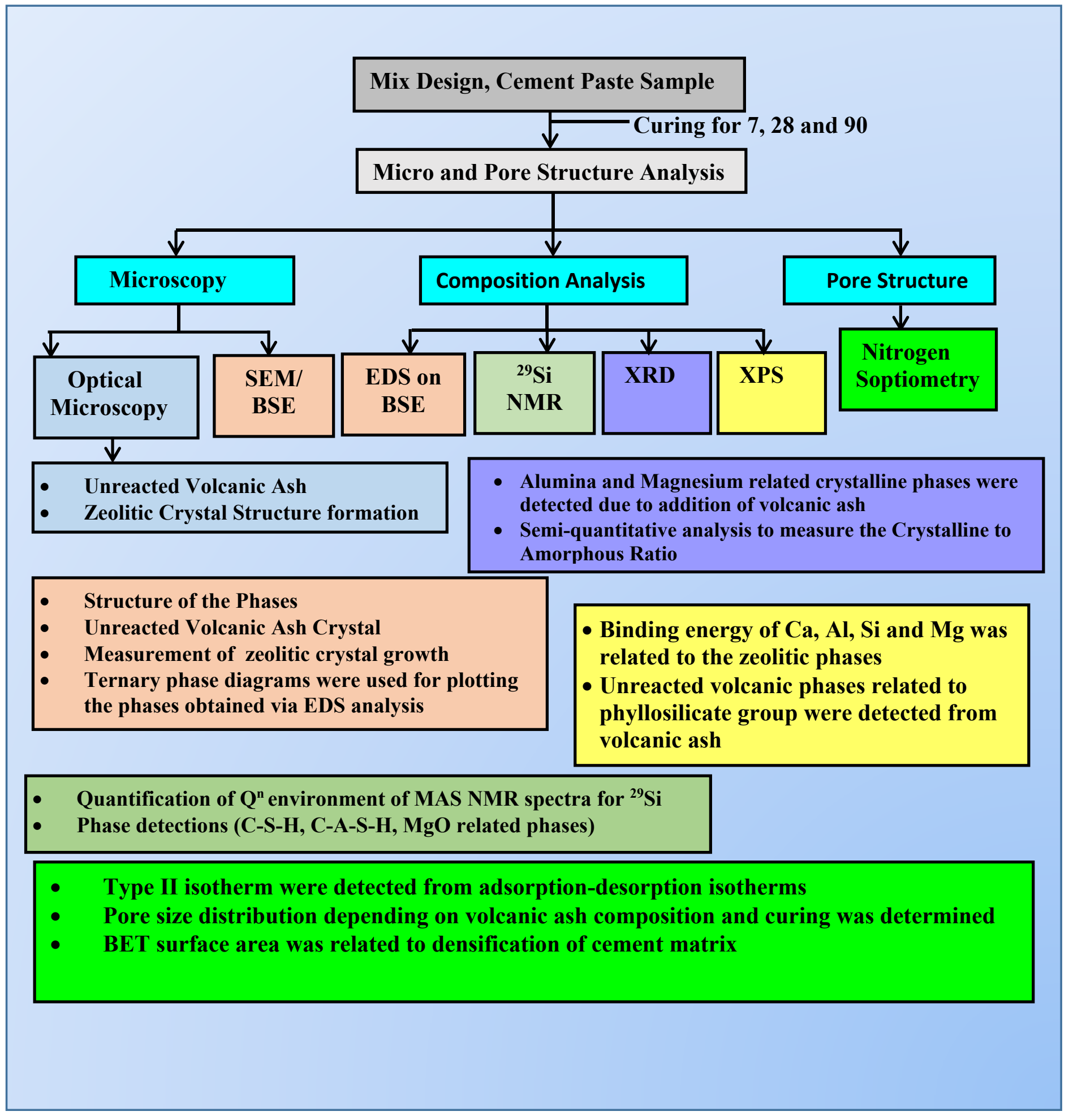




\section{Appendix}
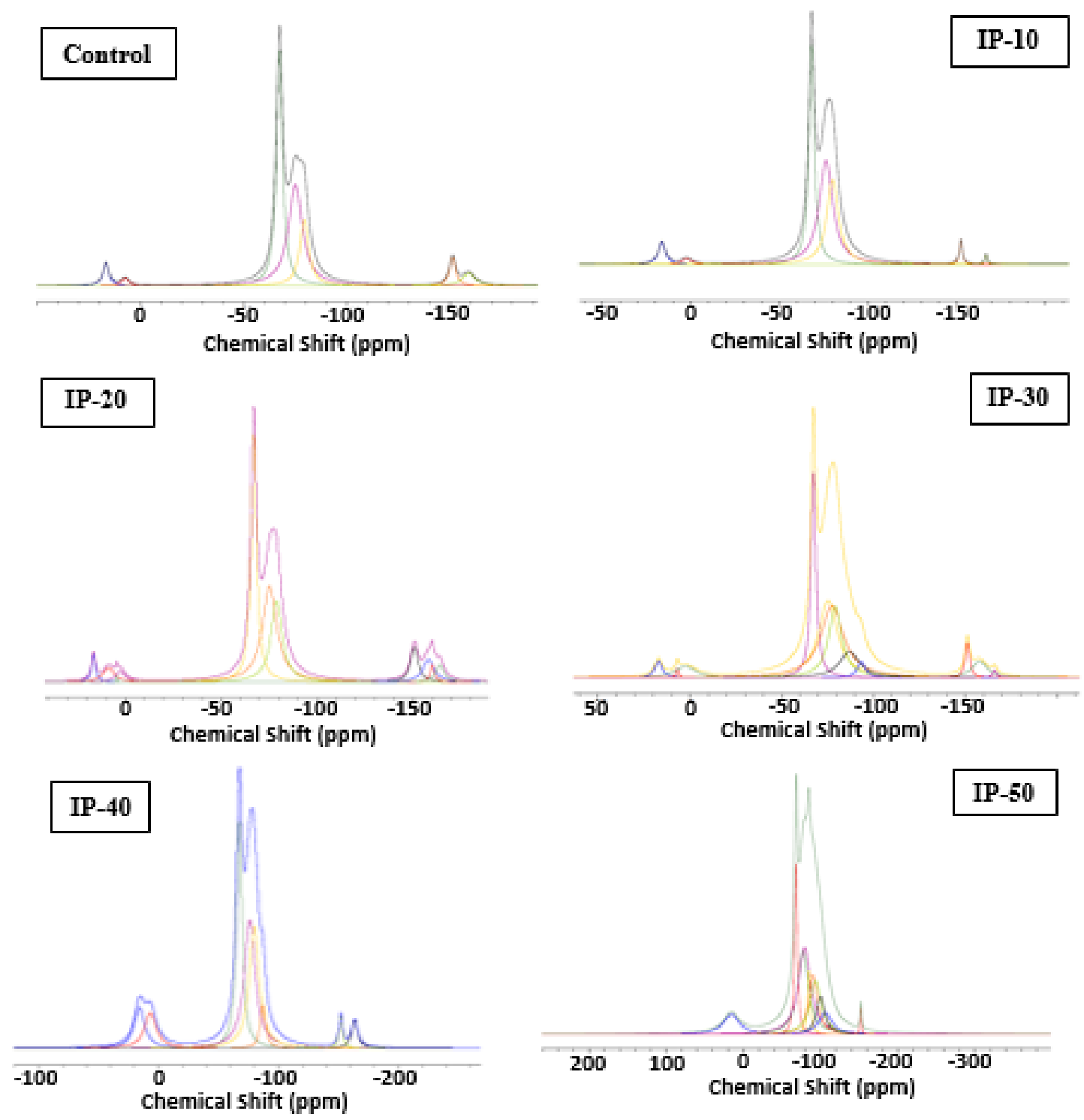

Fig A1. Deconvoluted ${ }^{29} \mathrm{Si}$ NMR Spectra for Control, IP10, IP20, IP30, IP40 and IP50 after 7 days of curing. 

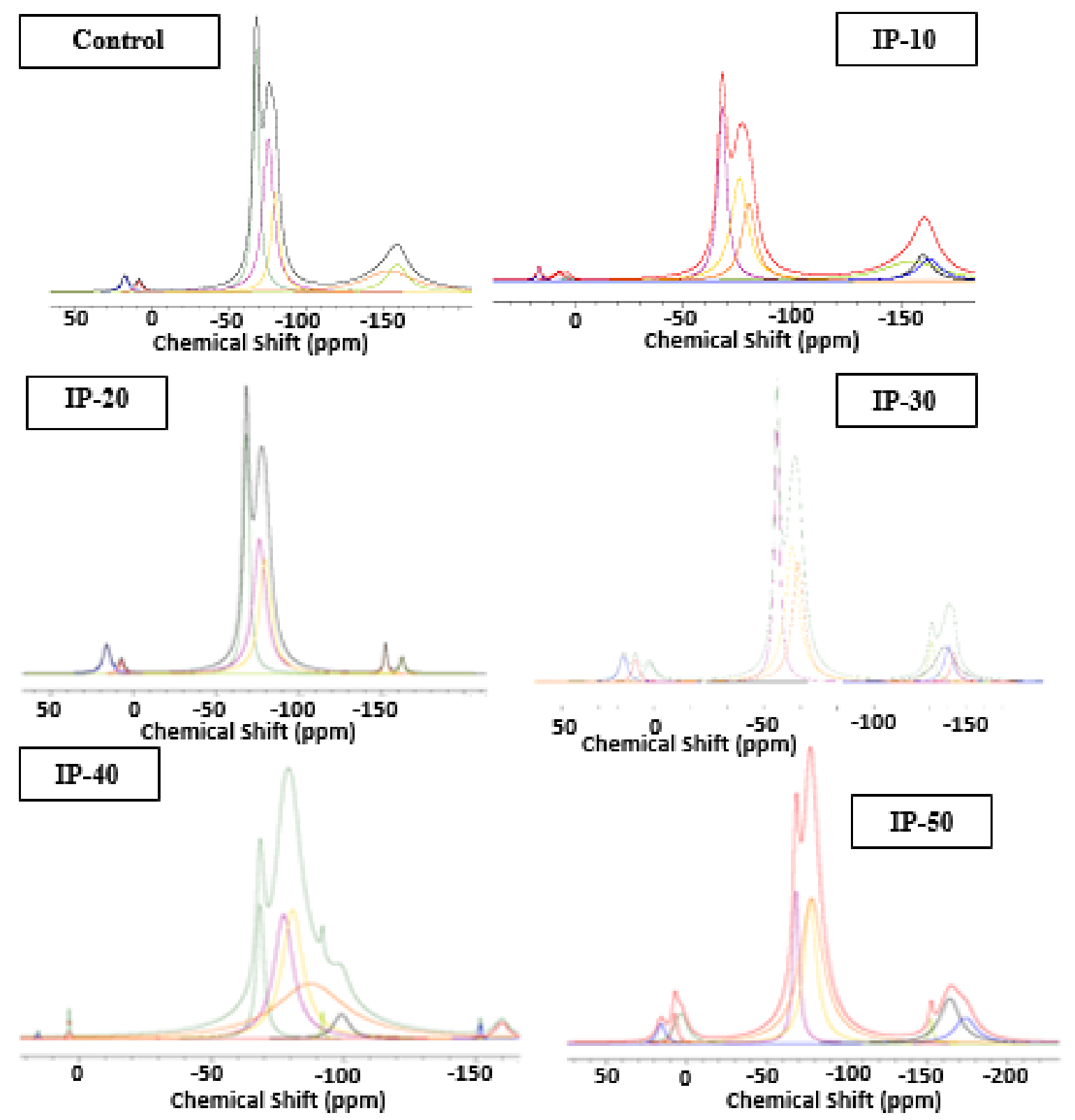

Fig A2. Deconvoluted ${ }^{29}$ Si NMR Spectra for Control, IP10, IP20, IP30, IP40 and IP50 after 28 days of curing. 

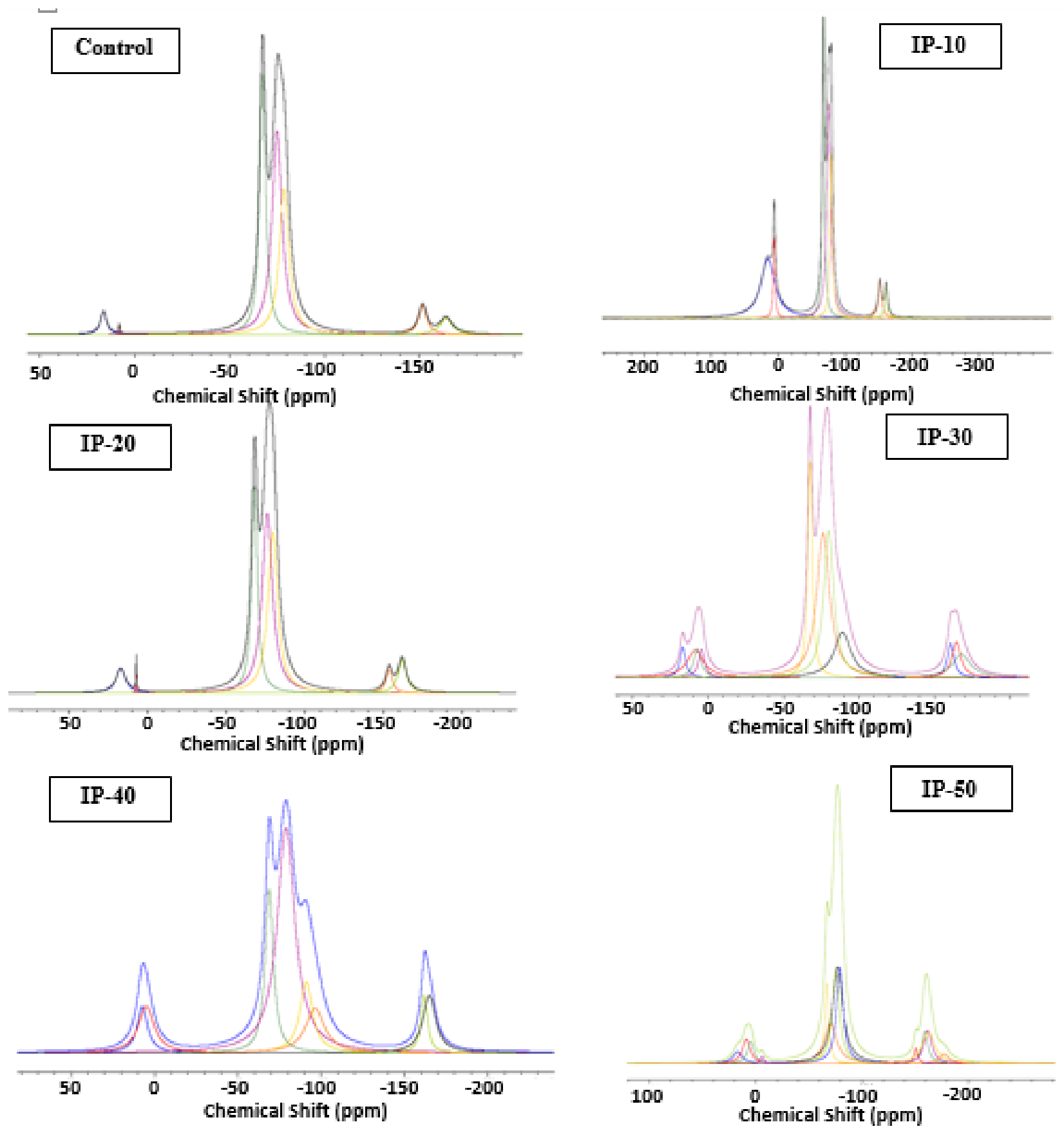

Fig A3. Deconvoluted ${ }^{29} \mathrm{Si}$ NMR Spectra for control (OPC), IP10, IP20, IP30, IP40, IP50 after 90 days of curing 